\title{
Towards a Natural Social Contract
}

In this chapter I will explain why and how the sustainability transition is humankind's search for a new social contract: a Natural Social Contract (conceptualization by author). I will start with a brief introduction on the origins of the social contract (Sect. 3.1), followed by a debate on the question whether there can be human progress without economic growth (Sect. 3.2) and a section on redesigning economics based on ecology, including circular and regenerative economies and cultures (Sect. 3.3). This chapter includes a debate on the role and scope of the free market (Sect. 3.4), as well as an examination of how the Anglo-Saxon and Rhineland models fare in this debate (Sect. 3.5). This chapter will also describe why we need a new social contract and what it should entail (Sect. 3.6). In doing so, I will embark on a quest for a Natural Social Contract (Sect. 3.7) and its theoretical foundations with multiple dimensions and crossovers (Sect. 3.8). This section concludes with an overview of fundamentals and design principles for a societal transformation towards a Natural Social Contract (see Table 3.4), which is a summary of Sect. 3.8 shaped as a course of action and is intended to help readers to grasp the core rationale of this book. For a better understanding of, and advancing the process towards, a Natural Social Contract this chapter presents a conceptual framework for Transformative Social-Ecological Innovation (Sect. 3.9), and how this will play out at various governance levels (Sect. 3.10).

\subsection{What Is a Social Contract?}

The sustainability transition constitutes a search for a new social contract. The core philosophy behind a social contract is that the members of a society enter into an implicit contract with the goal of living a better, safe life together (Kalshoven and Zonderland 2017). Such a contract includes agreements about public goods and services, for instance, as well as taxes, detailing how everyone contributes to and benefits from society. The contract describes the freedoms and obligations of all citizens: their rights and duties. This social contract does not exist in the sense that all 
citizens above the age of 18 sign a piece of paper. Rather, the social contract is an abstraction, a way of thinking that helps us understand how the world works that originates from the works of enlightenment philosophers (ibid. 2017).

Social contract theory has a long history in political philosophy. The main founders of classical contract theory are Thomas Hobbes (1588-1679), John Locke (1632-1704), Jean-Jacques Rousseau (1712-1778), and Immanuel Kant (1702-1804). Despite their differences, what these contract thinkers all have in common is that they tried to explain human society based on the idea that people once lived in some state of nature without rules and with unlimited freedom. In Hobbes's thinking, humankind naturally lives in a state of war (the conflict model), whereas Rousseau believed that humans were peaceful and timid in their pre-social state of nature, with social cohesion being created through consensus (the consensus model). According to Rousseau, the social contract enables humankind to pursue self-preservation by joining forces with others and sacrificing some individual freedoms for the will of the people. Rousseau used the metaphor of a contract to explore the relationship between individuals and their societies and legitimate government, and he argued that the ability to govern can only be legitimate if it comes from the people.

Following these enlightenment philosophers, contract thinking was given an important boost by the publication of A Theory of Justice, by social-liberal John Rawls (1971). There are also political philosophers, however, such as Michael Sandel and Charles Taylor, who criticize Rawls' work. Rawls does reserve a central position for the individual, for instance, but in Sandel's eyes fails to appreciate that all individuals are part of the community in some specific way (Sandel et al. 1985). Another important and more recent point of criticism is that 'Nature has had little or no intrinsic value for most (but not all) social contract theorists' (cf. O'Brien 2012), with no attention for the role of ecosystem services (Dobson and Eckersley 2006). The fact that ecological vulnerability translates into social and economic vulnerability, and a complex set of security and justice challenges, is an important omission in social contract theory.

In the past two decades, some scholars have argued that social contracts should be renegotiated due to the societal risks of climate change (O'Brien et al. 2009; Schellnhuber et al. 2011; Adger et al. 2013) and the ongoing ecological crisis (Jennings 2016), in particular given the co-evolving nature of risks and multi-actor influences on change (O'Brien 2012). Some scholars argue that the nature of environmental problems we face today requires new roles for states (Dryzek et al. 2002), while stressing several limitations of current social contracts: they can exclude those that may not recognize the legitimacy of government, and they can be influenced by non-democratic lobbying activities by powerful players (Weale 2011), and future generations are not represented. For instance, climate risks form a particular challenge for governments, given the related uncertainties and the often unequal distribution of risks and burdens (Pelling 2010).

A social contract is a more or less coherent whole of the freedoms, rights, rules and obligations that all residents have with regard to healthcare, education, labour, social security, and pensions, as well as in relation to our living environment, food, 
agriculture, nature, energy, water, the climate, and spatial planning. For example, all EU citizens have a right to the protection of fundamental rights, freedom of movement, and residence in the EU. The social contract might differ per country, but most European countries have similar rights and obligations as part of the social contract. Examples of such rules or obligations for EU citizens include compulsory insurance for medical expenses or compulsory education up to the age of 16. Likewise, all citizens are required to obtain a driving licence before driving a car and adhere to the traffic rules. Also pension schemes for employees, and phosphate rights for farmers are but some examples of the many arrangements in a social contract. The social contract, therefore, is key to the structure and functioning of our society. All citizens have a say in determining these arrangements through their voting rights, but there are more ways to give substance to a social contract. Each and every party in society can play a role in shaping and influencing the social contract, not only by means of our democracy (in various forms and at various levels), but also by bottomup governance through civil society involvement, a participatory and inclusive society, transition management, multi-party collaboration, social entrepeneurship, corporate social responsibility, exercising the right to demonstrate, collective action, social innovation processes, citizen engagement, and through local, national, European or global citizenship (see Sect. 3.8 - social dimension of a Natural Social Contract). For each of these processes, it is necessary to identify how the governance of a societal transformation towards a Natural Social Contract can be designed, facilitated, and realized in effective and legitimate ways (see Sect. 3.8-institutional dimension). Attempts to change established patterns always come up against resistance, rigidity, and/or normative questions as to the legitimacy, justness, methods, and direction of the transition (Grin 2016, p. 112; Meadowcroft 2009). Hence, it requires inclusive procedures to broaden legitimacy of decisions and actions, through stakeholder participation and involving all layers of society. It also requires deliberation on shared beliefs and values, common interests, procedural justice, and opportunities for multiple value creation and mutual gains. In Sects. 3.8 and 3.9, as well as in Chap. 4, I will provide more detail on the governance approaches that are required for such a transition. In Sect. 3.6, I will continue the above discussion on why we need a new social contract and what it should entail (Sect. 3.6). Before doing so, let us start with a debate on the question of whether there can be human progress without economic growth (Sect. 3.2) and a section on redesigning economics based on ecology, including circular and regenerative economies and cultures (Sect. 3.3). This chapter also includes a debate on the role and scope of the free market (Sect. 3.4), as well as an examination of how the Anglo-Saxon and Rhineland models fare in this debate (Sect. 3.5).

\subsection{Human Progress Without Economic Growth?}

The social contract is not only about our rights and freedoms as stated in the constitution, but also about how we fairly distribute the costs and benefits of what we produce and consume in a country and about a broader definition of welfare (see 
Sect. 2.1). It is clear, however, that a fair distribution of cost and benefits of what we produce and consume is not being achieved, since empirical studies show that inequality is increasing (Piketty 2013; Kremer and Maskin 2006). The assets are becoming more and more concentrated and a group of people is created that is extremely rich. On top of that, there is a well-established correlation between inequality and social and political instability (Russett 1964; Galbraith 2012; Stiglitz 2012, 2015). The problem, as Nobel Laureate Joseph Stiglitz argues, is that inequality can ruin democracy itself (Stiglitz 2012, 2015). Stiglitz argues that inequality is a choice - the cumulative result of unjust policies and misguided priorities (Stiglitz 2015).

Growing wealth inequality and the 2008 global credit crisis are merely symptoms of a deeper, systemic crisis. This can be traced back to decades of excessive production, consumption, and depletion of our natural resources and raw materials (Rotmans 2010). Over the past decade, a growing body of literature has been accumulating pointing out the contradiction between the pursuit of economic growth and ecological sustainability (Trainer 2011). We are now discovering that the ecological vulnerability translates into social and economic vulnerability, which is known as the paradox of prosperity (Sect. 2.1). For a more adequate conceptualization of the sustainability transition and the quest for a Natural Social Contract, we need a better understanding of the relationship between modern capitalist societies and the global ecological crisis. Naomi Klein, among others, has emphasized in 'Climate versus Capitalism' that the sustainability debate urgently needs to include a critical focus on economic systems (Klein 2015). Likewise, Mariana Mazzucato (2018) argues that we need to rethink capitalism, rethink the role of public policy and the importance of the public sector, and redefine how we measure value in our society, in particular since modern capitalist economies reward activities that extract value rather than create it (Mazzucato 2018). The literature on an alternative economy, written by economists such as Mariana Mazzucato, Paul Mason, Guy Standing, Colin Crouch, Eric Olin Wright, Paul Collier, and others, represents an expanding field of critical approaches to capitalism from various different angles. For instance, Paul Mason (2016) shows how the rise of the new digital economy is bringing about the decline of capitalism. According to Mason, capitalism cannot survive because primary resources (in particular information) are unrestrictedly available with an almost unlimited shelf life. This does not fit in an economic model based on private ownership. As a response, Mason argues for more cooperative schemes of free exchange - a 'sharing' economy to replace a predatory oneand more collective ownership as well. Likewise, Guy Standing (2019) argues for guarding our natural resources from private companies, by exploring the potential of the commons and commoning as an antidote against the erosion of society (see Sects. 3.8 and 4.3 for more information).

In particular since the 2008 global credit crisis the list with counter-proposals to unlimited economic growth has grown rapidly and is still counting. Many of these proposals are inspired by the 'Limits to Growth' report by the Club of Rome in 1972, followed by the UN Brundtland report on sustainable development 'Our Common Future' of 1987, and that led to the Millennium Development Goals dating from 
2000, and eventually to the UN Sustainable Development Goals (2015), as part of the '2030 Agenda for Sustainable Development'. Although the 2030 Agenda has the ambition to end poverty and create a sustainable economic growth path and protect the planet from degradation, it does not state how to deal with the trade-offs and synergies of the various goals (Van Vuuren et al. 2017). For example, 'although some improvement with respect to global poverty can be observed, historical development patterns especially for environmental issues have mostly been at odds with this ambition' (cf. Van Vuuren et al. 2017).

On the most radical side opposed to unlimited economic growth there is a social movement and academic debate on degrowth, which started in the beginning of the twenty-first century. The English term 'degrowth' was 'officially' introduced at the 2008 conference in Paris on Economic Degrowth for Ecological Sustainability and Social Equity, which also marked the birth of degrowth as an international research area (Demaria et al. 2013). Kallis et al. (2018) review the broader literature relevant to degrowth debates.

The key propositions from this literature on degrowth are that economic growth is not sustainable and that human progress without economic growth is possible. More specifically, it argues that an equitable downscaling of production and consumption increases human well-being and enhances ecological conditions at the local and global level, in the short and long term (Schneider et al. 2010). According to Schneider et al. (2010) degrowth theorists and practitioners support an extension of human relations instead of market relations, demand a deepening of democracy, defend ecosystems, and propose a more equal distribution of wealth. Schneider et al. (2010) make an important distinction between depression, i.e. unplanned degrowth within a growth regime, and sustainable degrowth, a voluntary, smooth, and equitable transition to a regime of lower production and consumption (ibid.).

In addition to degrowth theorists there is burgeoning emerging literature, from diverse origins, with counter-proposals to unlimited economic growth. This varies from literature on steady-state economy (Daly 1973; O’Neill 2012; Kerschner 2010) to green growth (Ekins 2000; Hallegatte et al. 2011; Jänicke 2012; OECD 2011; European Commission 2011; UNEP 2011), to circular economy (Webster 2013, 2014; Ellen MacArthur Foundation 2015; EU Commission 2014; Murray et al. 2017; Prieto-Sandoval et al. 2018; and many others) and regenerative economy (Fullerton 2015; Moreno and Charnley 2016; Raworth 2017; Wahl 2016), with multiple definitions and distinctive developments in different contexts (Webster 2013; Lieder and Rashid 2016).

The green growth discourse has been the most dominant in the past 10 years, not in the least because the green growth concept was embraced by key global international organizations, including UNEP, the OECD, the European Commission, and the Global Green Growth Institute (OECD 2011; European Commission 2011; UNEP 2011) and eventually led to the adoption of the '2030 Agenda for Sustainable Development' by the UN member states in 2015 .

More recently, however, the green growth discourse has been increasingly criticized, especially as economic growth is still a necessity in the proposed 'green' economies. First, a major criticism is that both neoliberal and keynesian 
economic approaches assume that prosperity stems from healthy GDP growth, but do not recognize biophysical limits to exponential growth, ignoring important lessons from ecology and thermodynamics about the natural limits of growth. In any case, this will reach a certain point where the incremental income is overtaken by the incremental damage, thereby decreasing global wealth (Hoffmann 2015; Fullerton 2015). To illustrate, a recent estimate shows that the "hidden social and environmental costs' of the global food system and land use amount to USD 12 trillion, which is $20 \%$ more than the market value of USD 10 trillion (Pharo et al. 2019). Second, using GDP as the primary measure of our economic health does not accurately assess the economy or the state of the world and the people living in it (Van den Bergh 2017; Stiglitz 2019a, b). Third, there is a lot of criticism that the failure of market forces is solved by enlarging the market and introducing new market mechanisms (Fatheuer et al. 2015). This is done, among other things, by redefining the relationship between nature and the economy, in order to allow the market to arrange matters that were previously beyond its reach, such as pricing ecosystem services. This hides the many structural causes of the environmental and climate crisis. The result is a new version of the concept of nature as natural capital and the economic services of ecosystems, but it does not change the economic growth paradigm. New market mechanisms such as trading biodiversity credits or carbon credits in many cases do not prevent the destruction of nature, but only organize it along market lines (Fatheuer et al. 2015).

In a study by Van den Bergh (2017) 'agrowth' is proposed as an alternative to the disjunction between the 'green growth' and 'degrowth' positions. As it is impossible to know for sure whether growth and a stable climate are compatible, van den Bergh considers that it is better to be agnostic about growth (a-growth) and proposes a strategy that discounts GDP as an indicator, 'since growth is not an ultimate end, not even the means to an end' (Van den Bergh 2017). GDP is a measure of what the economy produces, but not for broader welfare. Nobel Prize laureate and pre-eminent economist Joseph Stiglitz points out that the interrelated crises of environmental degradation and human suffering of our current age demonstrate that 'something is fundamentally wrong with the way we assess economic performance and social progress'. He argues that using GDP as the chief measure of our economic health does not provide an accurate assessment of the economy or the state of the world and the people living in it (Stiglitz 2019a, b). By contrast, there are many non-monetary ways of measuring well-being (Mazziotta and Pareto 2013; Allin and Hand 2017; Fleurbaey and Ponthière 2019; Veneri and Murtin 2019; Hoekstra 2019). Many things of value in life cannot be fully captured by GDP, but they can be measured by metrics of health, education, political freedom, and metrics of sustainability, for example, to measure to extent of resource depletion (or circularity), pollution, energy use, climate change, biodiversity, ecosystem services, and so on.

Jeroen van den Bergh (2017) points out that 'green growth' is the dominant strategy among those accepting climate change as a serious threat and searching for solutions which minimize growth effects. Citing van den Bergh: 'The Paris climate agreement reflects this, through its voluntary national pledges without back-up from 


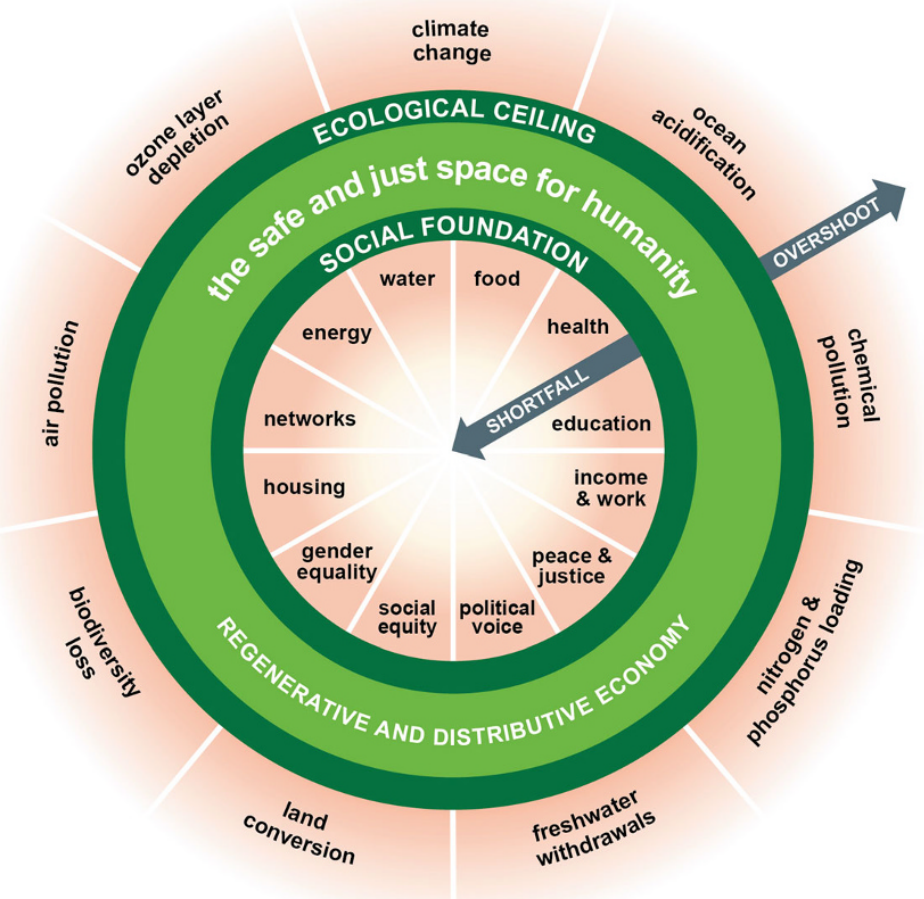

Fig. 3.1 Doughnut economy (Raworth 2017)

globally consistent policies. One must expect non-compliance, energy rebound and carbon leakage as a result, promising the agreement to be highly ineffective' (Quote from interview by AUB, 2017).

In Kate Raworth's book Doughnut Economics (2017) she argues that markets are inefficient and growth cannot continue unpunished. The carrying capacity of the earth must be respected and the economy must offer all people a decent life. Raworth uses the doughnut metaphor for this (see Fig. 3.1). The dough section of the doughnut represents a sustainable economy, the empty heart indicates the social deficits that may occur and marks the outer edge when ecological ceilings are exceeded. This means that the economy must adapt to the social and ecological preconditions, even if this would slow down economic growth. Between the social and planetary boundaries there is an environmentally safe and socially just, in short sustainable space within which humanity can flourish (Raworth 2017).

As such, her book is a counter-proposal to mainstream economic thinking that formulates conditions for a sustainable economy. Raworth calls for bringing 'humanity back at the heart of economic thought' (Raworth 2017). She argues that not everything can or should be left to the market, that the 'rational actor' model of economic conduct is problematic and that we cannot rely on the processes of growth 
to redress inequality and solve the problem of pollution. This plea echoes the work of many others, such as Nobel prize laureate Elinor Ostrom, who argued that 'neither the state nor the market is uniformly successful in enabling individuals to sustain long-term productive use of natural-resource systems' (Ostrom 1990). According to Ostrom, the joint and sustainable management of commons cannot succeed without institutions for collective action (ibid.). Based on extensive empirical research she showed that common pool resources need not succumb to the so-called tragedy of the commons (exploitation by someone taking more than their share) if a system of checks and balances prevails (see Sect. 4.4).

\subsection{Redesigning Economics Based on Ecology}

In the past decade the above mentioned counter-proposals to unlimited economic growth have been subject to an increasingly broad debate in the scientific as well as the policy community. A wide variety of initiatives and programmes, from local to global level, are being elaborated, operationalized, and implemented, for example, in the form of circular economy and closely related concepts, such as regenerative economy. While these two concepts are not exactly the same, both with multiple definitions, the commonality between both concepts is their key proposition that wealth creation can be decoupled from the consumption of finite resources. Bottom line is that these new economic models are using the 'universal principles and patterns underlying stable, healthy, and sustainable living and nonliving systems throughout the real world as a model for economic-system design' (Fullerton 2015). Redesigning our industrial system of production and consumption around the circular patterns of resource and energy use that we observe in ecosystems is only one example of redesigning our economy using the insights of ecology (Wahl 2016).

The concept of the circular economy (CE) has become very popular in Europe and increasingly other global regions. It has been a catalyst at European policy level (Webster 2013) and has become influential across business circles (Howard et al. 2019). It has become so popular because it offers a solution that will allow countries, firms, and consumers to reduce harm to the environment and to close the loop of the product lifecycle (EU Commission 2014; Murray et al. 2017; Prieto-Sandoval et al. 2018), which stands in sharp contrast to the deeply rooted and intensive linear economic activity that is depleting the planet's resources (Prieto-Sandoval et al. 2018).

More than 100 different definitions of circular economy are used in scientific literature and academic journals. There are so many different definitions on Circular Economy because the concept is applied by a very diverse group of researchers and professionals (Kirchherr et al. 2017). Definitions often focus either on system change or on resource use. According to Korhonen et al. (2018), definitions that focus on system change often emphasize three elements, namely closed cycles, renewable energy, and systems thinking. Definitions that focus on raw material use often follow the 3R approach, namely 'Reduce' (minimum raw material use), 'Reuse' (maximum reuse of products and parts), and 'Recycle' (high-quality reuse of raw materials). 


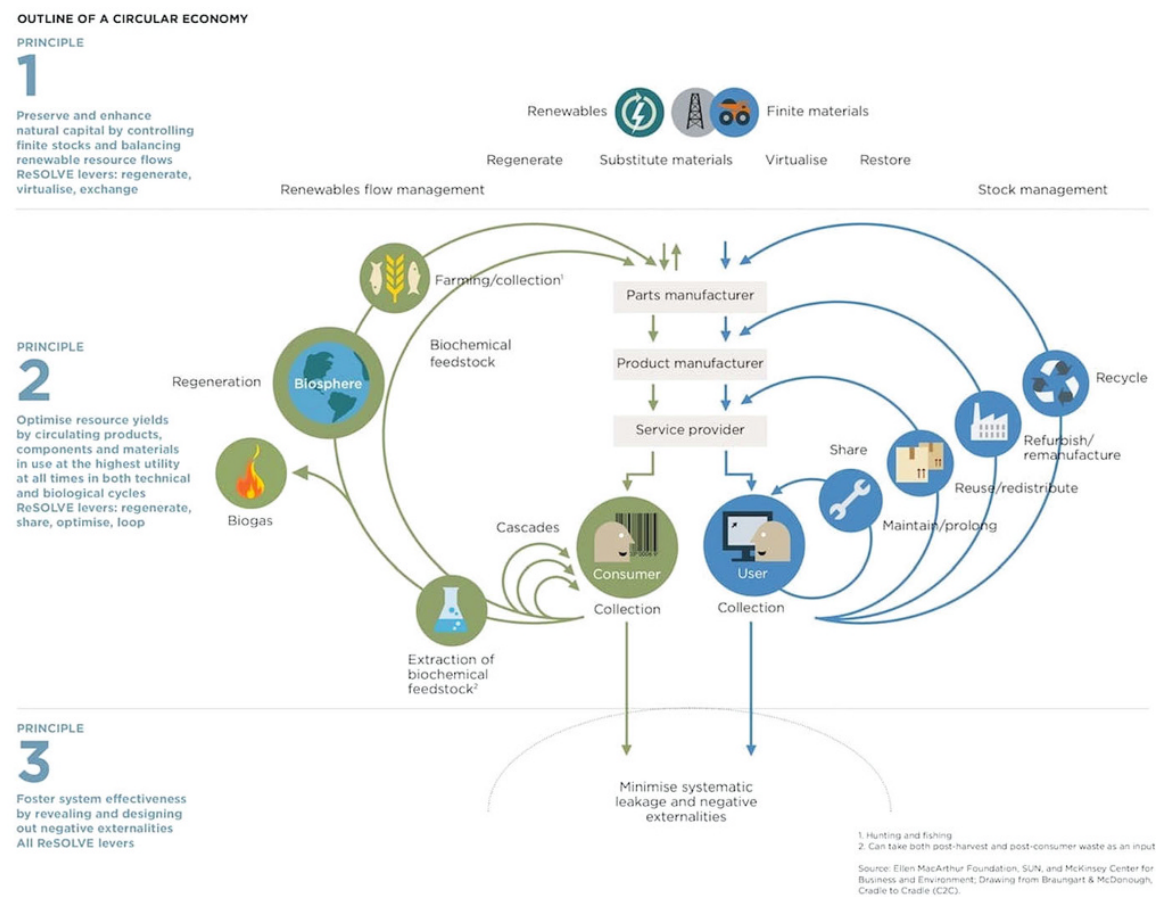

Fig. 3.2 Outline of a Circular Economy (Ellen McArthur Foundation 2015)

However, with a definition that only focuses on the use of raw materials, there is a risk that only optimization and efficiency improvements within existing systems are looked at, without the system itself being modified. Moreover, there is no guarantee that simple strategies of material recycling, as propagated by the various definitions of this concept, will lead to ecological sustainability (Desing et al. 2020) or to social justice and an inclusive society.

For example, some researchers argue that social inclusivity is a necessary part of the circular economy (Korhonen et al. 2018). In short, the transition from a linear economy to a circular economy does not only mean adjustments to reduce the negative effects of the linear economy. Rather, it is a systemic shift that builds long-term resilience, generates business and economic opportunities, and delivers environmental and social benefits (Ellen MacArthur Foundation 2015).

In the report 'Towards a Circular Economy', the Ellen MacArthur Foundation/ McKinsey schematically outlines the principles of the circular economy. See Fig. 3.2.

The British Standards Institution (BSI 2017) introduced six key principles of circular economy (for more details see Sect. 7.4):

1. System thinking: understand how your business impacts the whole ecosystem.

2. Innovation: manage resources for more value creation. 


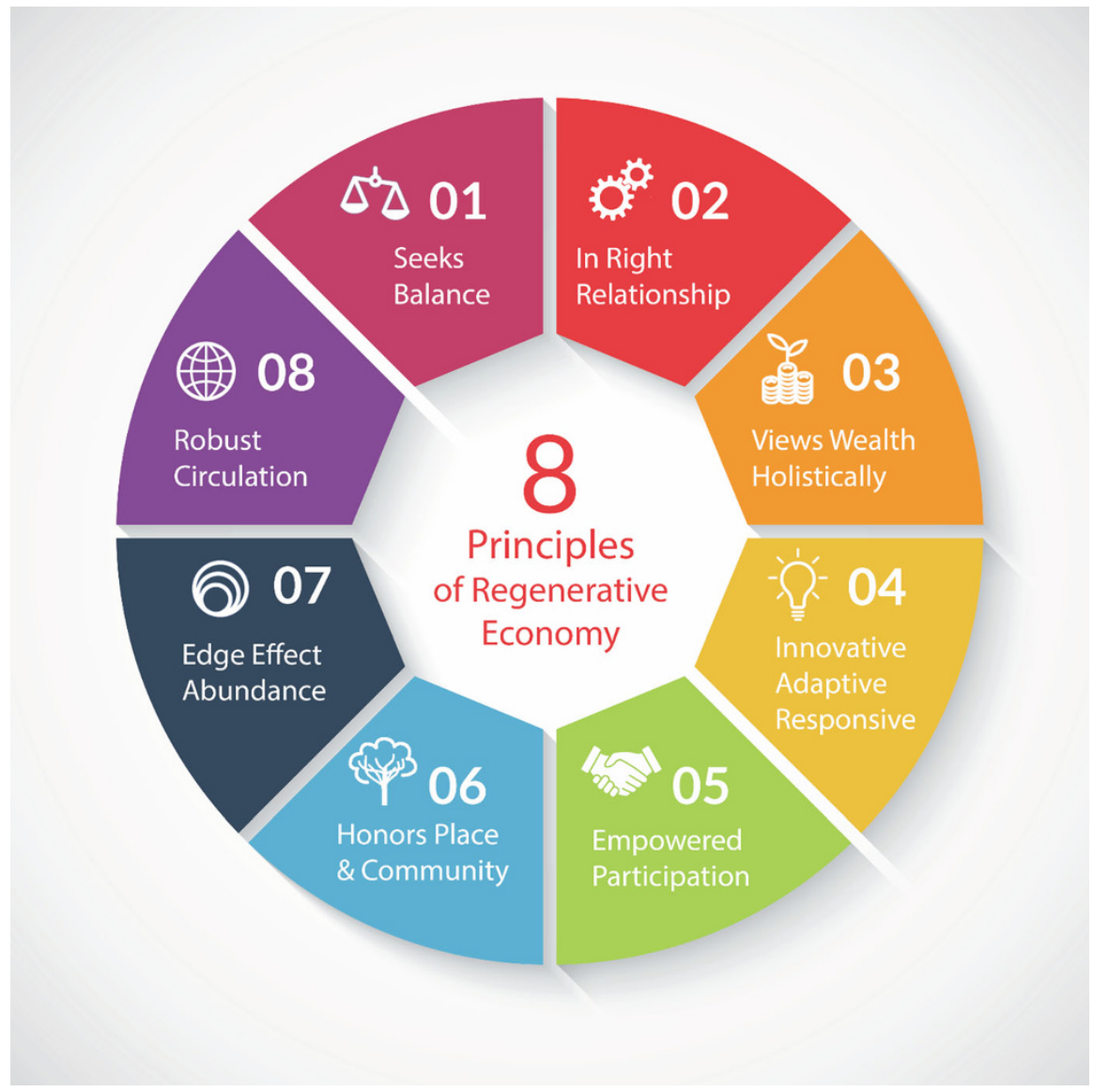

Fig. 3.3 Principles of a Regenerative Economy (Adapted from Capital Institute, 2020)

3. Stewardship: take responsibility for the ripple-effect impacts that come up from your business activities.

4. Collaboration: secure benefits at system wide level by strong cooperation in the value chain.

5. Value optimization: keep materials at the highest value and function quality.

6. Transparency: reveal to everyone the environmental impact of all your business activities.

In addition to Circular Economy, which is primarily focused on closing the loop of the product lifecycle, the model of Regenerative Economy is more holistic and explicitly builds on the natural design principles of healthy ecosystems (see Sect. 4.4). The principles of a regenerative economy are visualized in Fig. 3.3. Fullerton (2015) explains that ' a Regenerative Economy maintains reliable inputs and healthy outputs by not exhausting critical inputs or harming other parts of the broader 
societal and environmental systems upon which it depends'. According to Fullerton, Regenerative Economy is 'a theory of political economy that transcends the contemporary debate between the neoliberal economics preferred by conservatives on the political right and the Keynesian economics generally preferred by liberals on the political left' (ibid., page 40-41).

Taken together, the above debate marks an ongoing paradigm shift towards circular and regenerative economies and cultures. In Part III of this book I will apply these new economic models, among others, within the context of the transition to a sustainable and healthy agri-food system (Chap. 6) and urban sustainability transitions (Chap. 7).

In the following sections I would like to draw attention to the consequences of this ongoing paradigm shift for existing social contracts. It requires a debate on the role and scope of the free market and a critical reflection on the Anglo-Saxon and Rhineland model which currently determine the organization and functioning of capitalist societies.

\subsection{Debate on Role and Scope of the Free Market}

Since the 1970s, the market economy in many countries, mostly Western countries, has silently developed into a market society (Sandel 2012), which means the way people live together is dominated by individualism, self-interest, the free market, and a focus on profit and economic growth, shifting social and ecological values and interests to the background. Since the 1970s, and the following decades, many Western countries were too easily involved in the story that if the market arranges it, it is by definition better and more efficient.

Prof. Dr. Kim Putters, Director of the Netherlands Institute for Social Research (SCP), explains the problem of a market society as follows (AWVN 2016): 'The privatisation policy pursued by the government in recent decades has made a significant contribution to over-individualisation. Citizens have been turned into customers, but customers behave differently from citizens. Customers demand what they have paid for but feel no duty to the community. If people do not feel they are co-owners of the community's collective goods, such as the local park or their neighborhood, there are no collective standards. As a result, they never question what effect their behaviour has on the community'. Instead, citizens have increasingly started deriving their identity, security, and social status from consumption. A general passion for excess and materialism has developed, as well as a focus on beautiful, luxurious, and expensive items.

The triumphal march of the free market began in the early 1980s, after which the shift from a market economy to a market society has seen Western society become gradually more focused on individualism, the free market, and economic growth. Academic literature (see Rojas 2014 for an overview) emphasizes that our capitalist market society is an ideal foundation for consumer society, resulting in excessive mass consumption, environmental pollution, and depletion of natural resources. A capitalist market society usually rewards activities that extract value rather than 
create it (Mazzucato 2018). According to economist Mariana Mazzucato (2018) we will need to rethink capitalism, rethink the role of public policy and the importance of the public sector, and redefine how we measure value in our society (Mazzucato 2018).

A market economy is a valuable, effective tool for organizing productive activity. However, when market values permeate every aspect of human lives, and when market economy silently develops into a market society, in which social relationships are formed in the image of the market, it may become problematic (Sandel 2012). In his book 'Not everything is for sale' (2012), American political philosopher Michael Sandel points out the disadvantages of a society run by market values. For the majority of policies, such as those related to climate change, agriculture, water management, nature, biodiversity, education, healthcare, housing, transportation, it is important to engage in a debate on the role and scope of the free market. Sandel identifies two important drawbacks of a market-based society: (1) inequality and (2) corruption. Sandel explains that in a society where everything is for sale, people with few resources struggle more than people with ample resources, which leads to inequality. The more that money can buy, the more important money or the lack thereof will become. This is particularly problematic when money also buys access to social services, such as education and healthcare. This is also a problem within the sustainability transition, especially if sustainability is mainly framed as a matter of ethical consumption. It is easier for people with ample financial resources to spend money on sustainability than people who are not as wealthy. In that case, the moral choice will always be the more expensive choice. The risk is that this may create separate worlds: a 'green class' versus a 'grey class', where ecological and economic inequality go hand in hand. As a result, the gap between the rich and poor is widening, further exacerbated by the commercialization of social life (Sandel 2012). The second reason Sandel (2012) identifies is the corrupting effect of the market. Putting a price tag on everything opens the door for corruption, as it facilitates abuse of power and money. This is why we need a public debate as to where market forces should and should not play a role. Society will have to determine how important aspects of life such as healthcare, education, family life, nature, food, art, and civic duties should be valued.

Citizens cannot rely on the market to solve social problems such as social inequality, climate change, and other environmental problems. In his book Economics for the common good, Nobel laureate Jean Tirole explains that the best solution for climate change is putting a price on greenhouse gases. This, Tirole believes, is the only way, although he does add a careful analysis of why this solution will not be successful either (Tirole 2017).

Take, for instance, the 1997 Kyoto Protocol, which aimed to reduce global greenhouse gas emissions by introducing various new market mechanisms, backed by industrialized countries:

1. Emissions trading: a country or polluter with more carbon emissions can buy the right to emit more from a country or party that emits less.

2. Clean development mechanism (CDM): industrial countries can finance emission reduction projects in developing countries, such as by providing financial 
support to forestry or soil protection initiatives. In exchange, they receive credits (carbon credits) that allow them to emit more themselves, so that they do not have to cut emissions in their own country.

In a nutshell, countries or polluters can use financial injections in developing countries to buy permission to pollute. According to critics, these measures make the Kyoto Protocol a failed agreement (Gilbertson and Reyes 2009; Rosen 2015). Even the World Bank, a proponent of carbon trading, highlights the various shortcomings of the CDM (World Bank 2010).

There is a risk of introducing similar market forces when pricing the so-called ecosystem services. An ecosystem service is a benefit provided to people by an ecosystem, including production services (food, water, wood), regulating services (air purification by greenery and forests, water treatment by wetlands, pest control, pollination, water and climate regulation), cultural services (recreation, healthcare, cultural history, inspiration and religion), and support services (soil formation, primary production, the nutrient cycle, and biodiversity). The advantage of putting a price on these ecosystem services is that it generates awareness, especially since these services are often invisible, public goods. However, there is a risk that pricing ecosystem services can bring market forces into play, turning natural capital into an asset that can be appropriated, used, and traded by humankind. To present this from happening, regulation is required that curbs the adverse effects of market forces and guard ecological boundaries. To open the door for regulation, though, necessitates a public debate about the role, scope, functioning, and consequences of the free market and the associated norms and values. For example, 'since climate change and other threats occur over multiple scales and across the very long run, they demand governance and tools like incentives and feedback loops that act as guard rails and, where necessary, limits that coordinate across scales and focus on the longterm' (cf. Fullerton 2015).

In the past two decades, there has then been a move in environmental economics to regard such things as natural capital and ecosystems functions as goods and services. (e.g. Millennium Ecosystem Assessment 2005). However, this is far from uncontroversial within ecology or ecological economics due to the potential for narrowing down values to those found in mainstream economics and the danger of merely regarding Nature as a commodity. This has been referred to as ecologists 'selling out on Nature' (McCauley 2006).

In short, more oversight and adequate regulations alone are far from sufficient to curb the adverse effects of market forces. The financial crisis, banking crisis, and debt crisis are merely symptoms of a deeper, systemic crisis. This can be traced back to decades of excessive production, consumption, and depletion of our natural resources and raw materials (Rotmans 2010). Today's economy was not designed to cope with the perverse effects of such practices and it therefore lacks long-term feasibility. Without a transition to a sustainable economy, we will automatically create the next crisis (Grin et al. 2010). 


\subsection{Anglo-Saxon Model Versus Rhineland Model}

Political analysts believe that the 2008 global credit crisis ushered in the bankruptcy of financial capitalism. When it became clear that banks had been taking uncontrolled, irresponsible risks that put the global economy in serious jeopardy, many European countries expressed their support for more government control over the financial sector.

Ever since, the Rhineland model seems to have been gaining popularity, with the focus shifting to include other stakeholders (the Rhineland model) than shareholders alone (the Anglo-Saxon model). To put it simply, the Rhineland model is the economic system traditionally used in the countries that the Rhine flows through (Switzerland, Germany, France, and the Netherlands) and related economies (the Scandinavian countries, Belgium, Luxembourg, and Japan). This model rests on a consultative culture, solidarity, an appreciation of craftsmanship and values other than money, such as quality and happiness.

The Rhineland model is diametrically opposed to the Anglo-Saxon model in its raw form, as can be found in the USA, Great Britain, and Singapore, where money often seems to be the only measure, shareholders have the final say, and processes must be managed as efficiently and cheaply as possible (Schouten and Spijker 2017).

These two models were identified and defined by Frenchman Michel Albert in his classic book Capitalism vs. Capitalism, published in the early 1990s. Bakker et al. (2005) highlight the key differences between these two models in Table 3.1.

The Rhineland model is typically associated with the social market economy that developed on the European content after the Second World War, especially in Germany, the Benelux, and Scandinavia. Ludwig Erhard, Germany's first Federal Minister of Economic Affairs (1949-1963) is considered the founder of the social market economy, which aims to achieve the greatest possible prosperity while providing the best possible social protection. The social market economy is seen as a process and had to continuously adapt to new circumstances, such as globalization, digitization, climate change, ageing populations, and migrations.

Since the 1990s, the Rhineland model has come under increasing pressure from Anglo-Saxon values, such as the highly instrumental approach to the free market, shareholder value, human capital, management/control, and accountability (Goodijk 2009). In the Netherlands, market thinking also crept into sectors that were traditionally regulated by the government, such as utilities, the post, public transport, and even healthcare.

This shift to a more Anglo-Saxon value system was in line with a major economic-political turnaround set in motion in the 1970s, which saw the market gain ground in a great many policy areas as state power diminished (Zuidhof 2014). This development is called neoliberalism by some, but its supporters in the Netherlands prefer terming it classical liberalism, inspired by the work of Friedrich Hayek and Milton Friedman. To illustrate Hayek's influence, Dutch Prime Minister and Liberal Mark Rutte has written several essays about Hayek, including in Elsevier (2007) and Vrij Nederland (2011), and has repeatedly highlighted the influence of Hayek's ideas on his politics. In general, since the 1970s the dominant form of 
Table 3.1 Differences between the Anglo-Saxon and Rhineland models (Translated and adapted version, based on Bakker et al. 2005)

\begin{tabular}{|c|c|c|}
\hline Model & & \\
\hline Aspect & Anglo-Saxon & Rhineland \\
\hline Focuses on & $\begin{array}{l}\text { Short-term profits: } \\
\text { - Shareholder value. } \\
\text { - Money is power. } \\
\text { - May the best man win. } \\
\text { - Win-lose. } \\
\text { - You are either with us or against } \\
\text { us. }\end{array}$ & $\begin{array}{l}\text { Continuity and trust: } \\
\text { - Customer satisfaction. } \\
\text { - Employee satisfaction. } \\
\text { - Shareholder satisfaction. } \\
\text { - Win-win. } \\
\text { - A more multi-faceted approach to } \\
\text { relationships. }\end{array}$ \\
\hline $\begin{array}{l}\text { Dominant } \\
\text { philosophy }\end{array}$ & Financial thinking & Industrial thinking \\
\hline $\begin{array}{l}\text { Performance } \\
\text { focused on }\end{array}$ & Next quarter & Continuity \\
\hline Acquisition & Power to capital & Protective structures \\
\hline $\begin{array}{l}\text { Organization } \\
\text { is }\end{array}$ & $\begin{array}{l}\text { Supportive 'money-making } \\
\text { machine' }\end{array}$ & $\begin{array}{l}\text { A working community, a 'necessary evil' } \\
\text { for realizing complex products }\end{array}$ \\
\hline Central focus & Money, power, and heroism & Expertise, substance \\
\hline Manager is & $\begin{array}{l}\text { An MBA, because managing is a } \\
\text { skill }\end{array}$ & $\begin{array}{l}\text { A hands-on foreman (cf. Guilds and their } \\
\text { Master's test) }\end{array}$ \\
\hline Expertise is & The responsibility of employees & $\begin{array}{l}\text { The responsibility of employees and the } \\
\text { organization }\end{array}$ \\
\hline Focus on & Personal utility & Personal dignity \\
\hline Motivation & Extrinsic (money, incentives) & Intrinsic (nature of the work) \\
\hline $\begin{array}{l}\text { View of } \\
\text { mankind }\end{array}$ & Mechanistic & Humanistic \\
\hline $\begin{array}{l}\text { Remuneration } \\
\text { depends on }\end{array}$ & Productivity & Position \\
\hline Labour & Is a cost factor & Has a social component \\
\hline Employees & Input & Embody the organization \\
\hline $\begin{array}{l}\text { Funding } \\
\text { through }\end{array}$ & The stock market & Banks and family \\
\hline Companies & Mostly public & Various business models \\
\hline National & $\begin{array}{l}\text { Minimum government } \\
\text { interference: the market governs } \\
\text { (the invisible hand) }\end{array}$ & $\begin{array}{l}\text { Government plays an active role. } \\
\text { Consensus between employers, } \\
\text { employees, and financiers }\end{array}$ \\
\hline Relies on & Military/hard power & Economic/soft power \\
\hline $\begin{array}{l}\text { Unilateral/ } \\
\text { multilateral }\end{array}$ & Unilateral & Multilateral \\
\hline Central focus & Individuals & Mutual relationships \\
\hline $\begin{array}{l}\text { Leading } \\
\text { principle }\end{array}$ & $\begin{array}{l}\text { Individual success: the American } \\
\text { Dream }\end{array}$ & $\begin{array}{l}\text { Collective well-being, culture, open, and } \\
\text { 'feminine' }\end{array}$ \\
\hline $\begin{array}{l}\text { Attitude to } \\
\text { minorities }\end{array}$ & The winner takes it all & Minorities get a share \\
\hline Bankruptcy is & The start of something new & The end \\
\hline $\begin{array}{l}\text { Focused } \\
\text { towards }\end{array}$ & The USA & Asia \\
\hline
\end{tabular}


Table 3.1 (continued)

\begin{tabular}{|c|c|c|}
\hline Model & & \\
\hline Aspect & Anglo-Saxon & Rhineland \\
\hline Driven by & Technology (D\&E) and market & Design and science $(\mathrm{R} \& \mathrm{D}(\& \mathrm{E})$ \\
\hline $\begin{array}{l}\text { The } \\
\text { Netherlands }\end{array}$ & $\begin{array}{l}\text { Country of traders: } \\
\text { Merchants } \\
\text { Preachers }\end{array}$ & $\begin{array}{l}\text { Country of innovation: } \\
\text { Ahead of the socio-economic curve } \\
\text { Ahead of the technological curve }\end{array}$ \\
\hline $\begin{array}{l}\text { Education } \\
\text { funded by }\end{array}$ & Government funds public schools & Government also funds private schools \\
\hline $\begin{array}{l}\text { Coordinated } \\
\text { by }\end{array}$ & Rules & Shared values \\
\hline Character & $\begin{array}{l}\text { Adventurous, exciting, and } \\
\text { passionate }\end{array}$ & Cautious, careful, prudent, boring \\
\hline $\begin{array}{l}\text { Relationship } \\
\text { between } \\
\text { businesses }\end{array}$ & Competition & Cooperation \\
\hline
\end{tabular}

capitalism is generally called neoliberalism and the Washington Consensus, with heavy influence from the free-market-oriented Chicago School of economics and the Hayek philosophy (Fullerton 2015). Since the 2008 global credit crisis, a resurgence of Keynesian and particularly post-Keynesian ideas has pushed back into the mainstream debate, calling for a greater role for the State in regulating free market capitalism (Fullerton 2015; Biebricher 2017).

Neoliberalism, or classical liberalism, is difficult to define, firstly because it consists of three major movements which each have a different view of the relationship between the economy and democracy and between the market and the state (Biebricher 2017). These movements disagree on the desirability of government intervention, though they do all agree that the government is responsible for creating the underlying conditions that the free market requires in order to flourish. The belief in the infallibility of the market as the ultimate truth teller is at the heart of neoliberalism, whereas opinions differ about whether this requires big or small government and what exactly the domain of government intervention is.

Ronald Reagan and Margaret Thatcher, the political figureheads of neoliberalism in the 1980s, started the process of liberalization with tax cuts and reining in the welfare state. After the fall of the Berlin wall in 1989, the capitalist camp was able to proclaim its political and socio-economic superiority. According to Francis Fukuyama, the global battle between capitalism and communism was won (Fukuyama 1992). Capitalism was declared the victor after the fall of communism, but what did that really mean? Which type of capitalism had won? Was it Reagan's and Thatcher's liberal capitalism or the type of capitalism practised in Germany and the Netherlands, among other countries? Had the Anglo-Saxon model or the Rhineland model triumphed (Bakker et al. 2005)? Sandel (2012) believes that, over the past decades, our market economy has, consciously or subconsciously, made way for a market society, dominated in many respects by the Anglo-Saxon model. 
In response to the consequences of the Anglo-Saxon model, such as shareholder capitalism, self-regulation, and excessive individualism, supporters of the sustainability transition are now looking for answers in new incarnations of the Rhineland model (see, e.g. Rotmans 2010; Latour 2018; Varoufakis 2019). The leading principle here is striving for a balance between government, the market, and civil society. Rotmans (2010) describes the renewed Rhineland model as follows: 'Anglo-Saxon values will make way for more harmonious relationships between the market and government, between labour and capital and between individualism and capitalism. The renewed Rhineland model is based on fundamental moral values such as well-being, quality, ecological preservation, long-term thinking, and "togetherness". These are all prerequisites for a sustainable economy. From a social point of view, this means, among other things, that professionals such as police officers, nurses, and teachers should not be regarded as mere production factors. They are professionals who must be able to develop and be rewarded for their performance. The slow decision-making process of the traditional Rhineland model, consulting with myriad interest groups, will be swapped out for effective cooperation with new coalitions in horizontal networks'.

\subsection{Looking for a New Social Contract}

In 2020 the Coronavirus pandemic shakes the world to its foundations and will probably create a new reality once the pandemic has been tackled. The weaknesses of a market-based society, primarily focused on economic growth and everincreasing circulation of goods and people, have been painfully exposed. First, the people working in health care, food production, education, and the police, who were regarded as mere production factors in a neoliberal model and who had to hold up their hands for a decent salary before the Corona-crisis, are now the heroes of society. Of course they already were, but appreciation for these professionals failed to materialize because it was overshadowed by the over-appreciation of the free market, market-based values, privatization, and unlimited economic growth. Second, another weakness exposed by the Corona pandemic is that a model of unlimited circulation of goods and people has substantially fueled the spread of disease around the world. Third, climate change promotes the emergence of serious disease outbreaks (Laaksonen et al. 2010; Rees et al. 2019), and the coronavirus will certainly not be the last causing large-scale societal disruption.

Before the Corona-crisis, the world witnessed a surge of massive civil protests in many countries in 2019, including Hong Kong, Chile, Bolivia, Ecuador, Guinea, Haiti, Honduras, Nicaragua, Malawi, Russia, Sudan, Zimbabwe, Egypt, Algeria, Iraq, and Lebanon, as well as in Europe, for example, in the UK, Spain, France, Germany, and The Netherlands. The trigger of these protests varied from country to country, but there are a number of underlying commonalities, all of which can be described as threats to the social contract. The common factors pushing people to protest include corruption, inequality, cost of living, climate justice, and political 
freedom, while in 2020 protests over racial injustice and police violence dominated the news.

One of the standout moments came in September 2019, when more than 7.6 million people took part in a week of climate strikes in 185 countries. The climate protesters demanded urgent action on the escalating ecological emergency, and some argued that politicians and governments had 'broken the social contract' by not anticipating and responding adequately to the climate crisis. Indeed, the purpose of the social contract is serving the common or greater good to ensure the sustainability of the society in question and protect the individuals within it. In other words, the social contract is expected to provide security and justice for all. If not, political authority loses its legitimacy, and the social contract will be eroded or will even fall apart, as illustrated by the Arab spring. Climate change and its effects are inextricably linked to complex questions of security and justice (see Huntjens et al. 2018) and therefore relates directly to the social contract.

The rising threats to the social contract on a global scale have led UN Secretary General Guterres to sound the alarm on 25 October 2019, urging leaders everywhere 'to listen to the real problems of real people'. He also stressed that the world 'needs action and ambition to build a fair globalization, strengthen social cohesion, and tackle the climate crisis'.

The question is, therefore, whether current social contracts can still provide an adequate response to the challenges of the twenty-first century, such as corruption, inequality, climate change, pollution, and depletion of natural resources. In recent years there have been several proposals to account for climate change (mitigation and/or adaptation) in current social contracts (e.g. see O'Brien et al. 2009; Schellnhuber et al. 2011; Adger et al. 2013, Jennings 2016). One such proposal is developed by the German Advisory Council on Global Change (WBGU) in 2011 (Schellnhuber et al. 2011), addressing the unsustainability of our current carbon-based economic model, and as response, the WBGU-report proposes a new social contract based on a transformation towards a low-carbon society. In the field of climate change adaptation, O'Brien et al. (2009) and Adger et al. (2013) propose to renegotiate social contracts between citizens and states as a primary mechanism for adaptation. Jennings 2016) provides an ethicist's reckoning with how our political culture, broadly construed, must change in response to climate change.

In this book I fully endorse above proposals, but also challenge them, given their limited focus on either climate change mitigation (e.g. Schellnhuber et al. 2011) or climate change adaptation (e.g. O'Brien et al. 2009; Adger et al. 2013) or a too structuralist point of view (e.g. Jennings 2016), with limited attention for how to realise change on the ground. In taking an actor-centric institutional perspective (see structure-agency debate in Sect. 3.9), my book addresses two mistakes: a too structuralist point of view (common in political economy) and voluntarism (common in actor-centric research of specific innovations). A broader and more existential societal transformation is required for asserting a sustainable and healthy future. It is true that most people are gradually realizing that global warming is a major problem, but is climate change not just a symptom of a deeper, systemic crisis? A new social 
contract should be able to respond to societal fault lines, the most comprehensive of which is the divide between humans and nature, as well as the deeply embedded capitalist economic logic, resulting in increasing wealth inequality as well as marketbased societies where citizens have been turned into customers and consumers and demand what they have paid for, but feel no duty to the community or environment. In current anthropocentric social contracts, natural resources are viewed to be used exclusively by humans, to serve the needs of humanity and the needs of our current economic systems with a singular focus on economic growth. The loss of biodiversity, environmental degradation, bio-industry, land, water, and air pollution, and fossil energy consumption, for instance, show that the way we deal with nature is profoundly disturbed. However, most of the scientific frameworks for sustainability transitions and transformation research remain limited by not reflecting on how deeply embedded the divide between humans and nature in combination with the capitalist economic logic has become in our current social contracts. Therefore I argue for a fundamental shift from our current anthropocentric and economic growth-oriented social contract towards a more ecocentric, regenerative, and natural social contract (see Sect. 3.7), which does justice to the natural position of humankind and society within a larger ecosystem, that of planet Earth.

Thinking about ways to improve the social contract, targeting a sustainable, regenerative, healthy and just society, can help policymakers, administrators and decision-makers, citizens, and professionals to make better decisions about how to organize our twenty-first century society.

\subsection{A Natural Social Contract}

The sustainability transition implies a large-scale societal transformation towards a Natural Social Contract, in which Transformative Social-Ecological Innovation (TSEI) will be needed in different fields and at different levels of scale (see Sect. 3.10 for examples).

The five decades from 2000 to 2050 will go down in history as the sustainability transition, by some called the 'Great Mindshift' (Göpel 2016) or the next 'Great Transformation' (Schellnhuber et al. 2011), referring to a redirection of civilization that recalls the advent of market economies described by Karl Polanyi in The Great Transformation (Polanyi 1944; Haberl et al. 2011; Leggewie and Messner 2012). The transformation to a sustainable, healthy, and just society is humankind's quest for a new social contract — in this book coined as a Natural Social Contract—which requires a fundamental shift from our current anthropocentric social contract towards a more ecocentric and regenerative social contract, acknowledging society as a social-ecological system (see Sect. 3.8). A Natural Social Contract is an unavoidable and logical response to the most comprehensive societal fault lines of our times, which can be traced back to two common denominators. First, the schism between humans and nature and the dominant anthropocentric world view that arose during the Enlightenment. Second, the capitalist economic logic, in particular the unsustainability of infinite economic growth in a finite world, and the belief in the 
infallibility of the free market, that arose after the Second World War. In particular since the 1970s, and the following decades, many Western countries were too easily involved in the story that if the market arranges it, it is by definition better and more efficient (Sandel 2012).

A societal transformation towards a Natural Social Contract constitutes an existential change in the way humankind lives in and interacts with its environment, in harmony with nature, and focusing on people as members of a community and as part of a natural ecosystem. It does justice to the natural position of humankind and society within a larger ecosystem, that of planet Earth. A Natural Social Contract enables humankind to pursue self-preservation and higher levels of well-being by joining forces with others and with nature while at the same time putting an end to unlimited economic growth, overconsumption, and over-individualization, for the benefit of ourselves, our planet, and future generations. Key differences of a Natural Social Contract compared to existing social contracts are described in Table 3.2.

Seeing humankind as part of a natural ecosystem is the opposite of the Western dominant social paradigm of a firm boundary between humanity and the environment. Bruno Latour (2012) argues that "the essence of the "modern constitution" lies in the fiction of an ontological separation between humans and society on one side and nature and non-humans on the other side'. In particular during the Enlightenment-from the seventeenth to nineteenth centuries-the separation between nature and human society became more dominant due to rationalists such as Descartes and Bacon, as well as Enlightenment thinkers such as Newton, Kant, Adam Smith, and Montesquieu. For example, René Descartes' (1596-1650) made a strict separation between humankind and the rest of the universe by claiming that only humans have a 'spirit'. The rest of nature, he believes, is only matter. Descartes' radical division is particularly important because it is such a clear representation of the dominant anthropocentric world view that arose during the Enlightenment (Mommers 2019). Descartes' main contribution is that he applies a varnish of rationality to the hierarchy of people in nature. In post-Enlightenment Europe, the idea that humankind is superior to nature is no longer an opinion; it is upgraded to a fact. If you disagree, you are not considered rational. This, effectively, set the schism between 'society' and 'nature' in stone (Patel and Moore 2017). As a result, 'modern societies have engaged in increasingly disruptive modes of interaction with the biophysical environment, and this is widely perceived as not simply a side effect, but a characterizing trait of modern societies' (cf. Jackson 2009). During this 'modernization' process in the past centuries, where humanity aspires to transcend nature and to control the external world, modern societies have also lost sight of some basic principles for life on earth in the long term and thus ignoring vital benchmarks for a sustainable and healthy society (see Sect. 4.5: design principles from nature). Contemporary scholars emphasize that natural conditions are not separate from social processes (Berkes et al. 2000; Anderies et al. 2004; Skandrani 2016). Within a Natural Social Contract, the term 'social-ecological system' is used 'to highlight the integrated concept of humans within nature and to address the delineation between social and ecological systems as artificial and arbitrary' (cf. Berkes et al. 2000). 


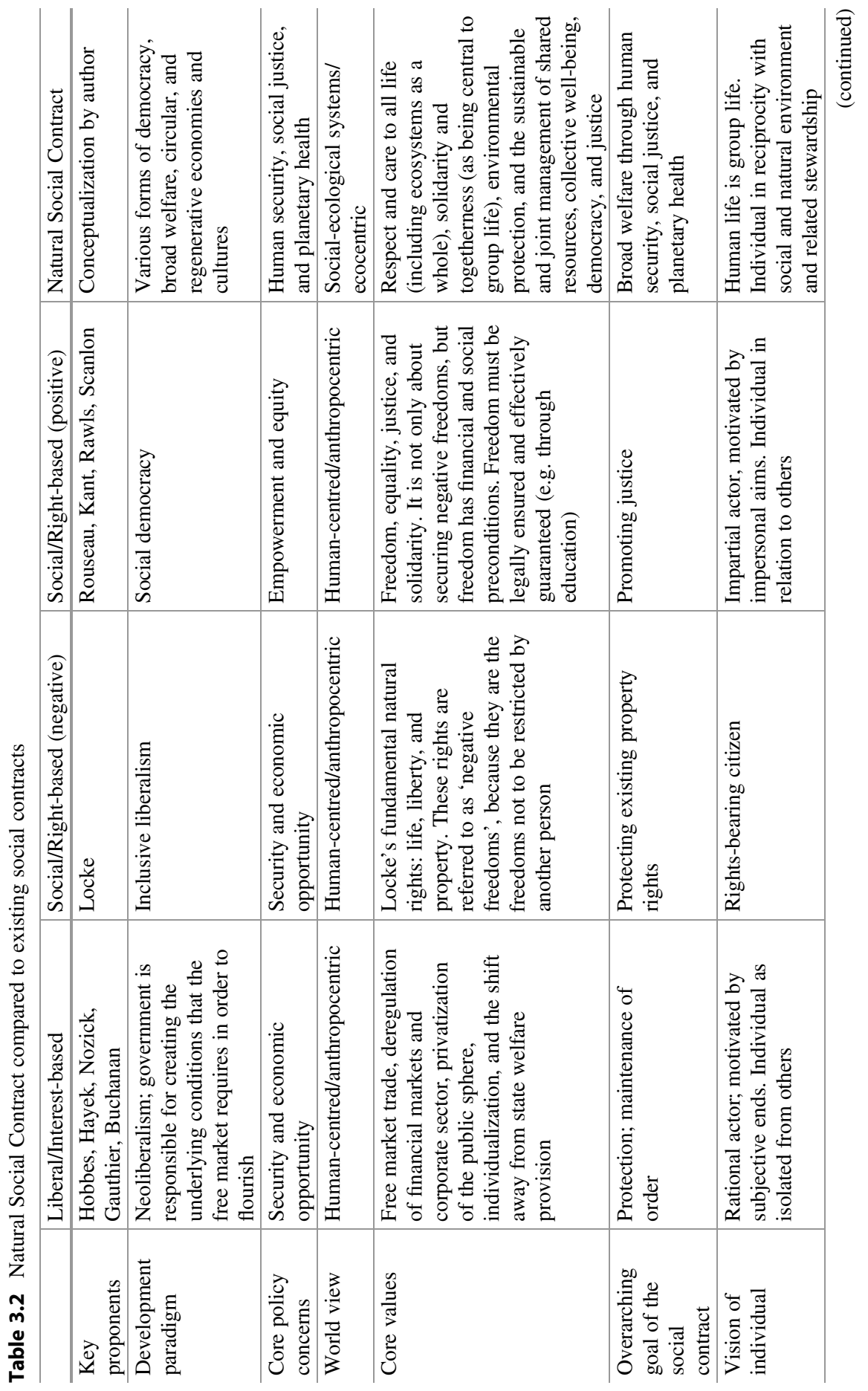




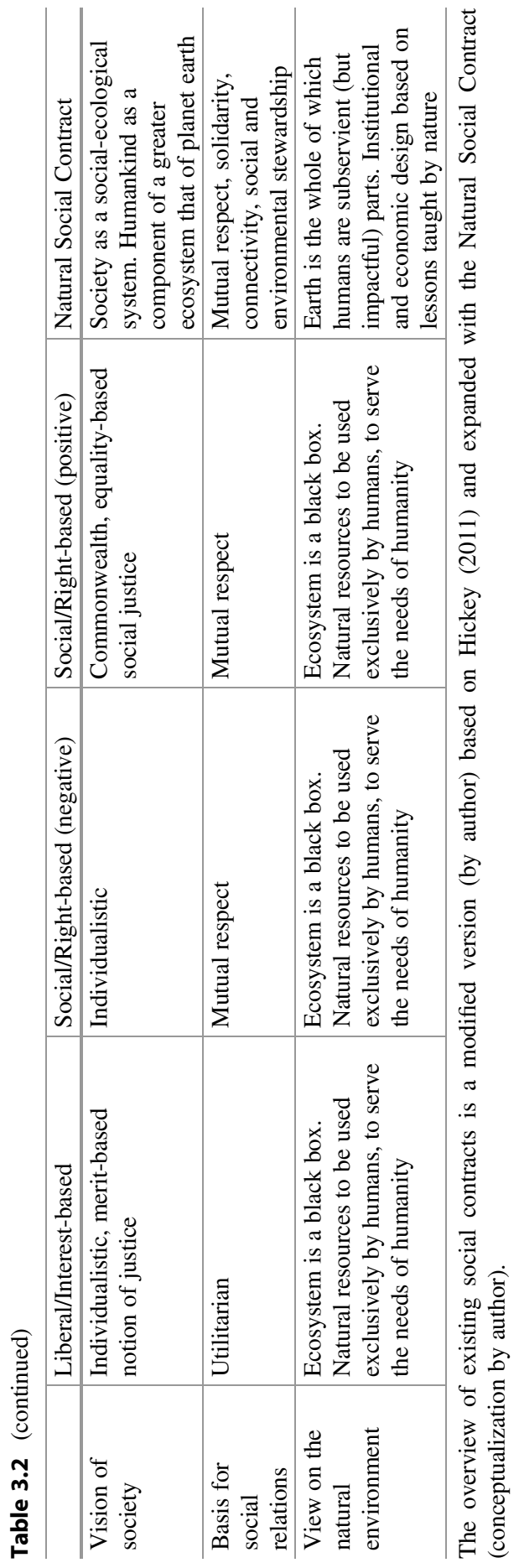




\subsection{Dimensions and Crossovers Within a Natural Social Contract}

Every society, and thus every social contract, consists of several dimensions, including an economic, social, ecological, and institutional dimension. Each of these dimensions consists of a multitude of interconnected heterogeneous components. These dimensions themselves are a complex, dynamic, self-organizing, and evolving entity, so the four dimensions together lead to an enormous complexity (Spangenberg 2005). Change or problems in one dimension thus affects all dimensions and vice versa. Finding leverage points alone is not enough; systemic change also requires good insight into the interrelationships, for example, via (non-linear) feedback loops, and how the desired outcome can be achieved with maximum synergy effects and minimal 'trade-offs' (Kennedy et al. 2018). The connections between the dimensions must enable permanent coevolution, when working on transformative change, but also means a high degree of path dependence, with choices from the past determining the current structure. This path dependency is a reason for institutional stability, since institutional pressures force organizations to adopt similar practices or structures to gain legitimacy and support (DiMaggio and Powell 1983, 2000), and these institutions become firmly rooted in taken-for-granted rules, norms, and routines (Seo and Creed 2002). A societal transformation will always be a battle to overcome vested interests, change existing systems and paradigms. This explains, among others, why major societal transformations take on average about 30 years, which is also a realistic timespan for some of the fundamental systemic changes required for a Natural Social Contract.

A Natural Social Contract as proposed in this book is an open and broad theoretical framework across multiple dimensions (i.e. social, ecological, economic, and institutional) that serves to start a dialogue about ways to improve the current social contract, targeting a more sustainable, regenerative, healthy, and just society. It can help policymakers, administrators and decision-makers, concerned citizens and professionals to make better decisions about how to organize our twenty-first century society. It is an open framework in the sense that it is open for additional predictors and moderators in every dimension if they have a documented effect. This theoretical framework is visualized in Fig. 3.4. A clear delineation between dimensions is not possible, given the broad scope and overlap of some of the theories mentioned, while the positioning of a theory or concept in one dimension is sometimes artificial (for the purpose of visualization), given its relevance for other dimensions. The theories and concepts included are described in various chapters of this book and brought together in this theoretical framework, although 'theoretical context' is perhaps a better description. In any case, the purpose is to give a semistructured overview of relevant theories and concepts that provide a better understanding of a Natural Social Contract. Each dimension, and possible crossovers with other dimensions, will be briefly described below (with reference to sections in this book for more detail). 


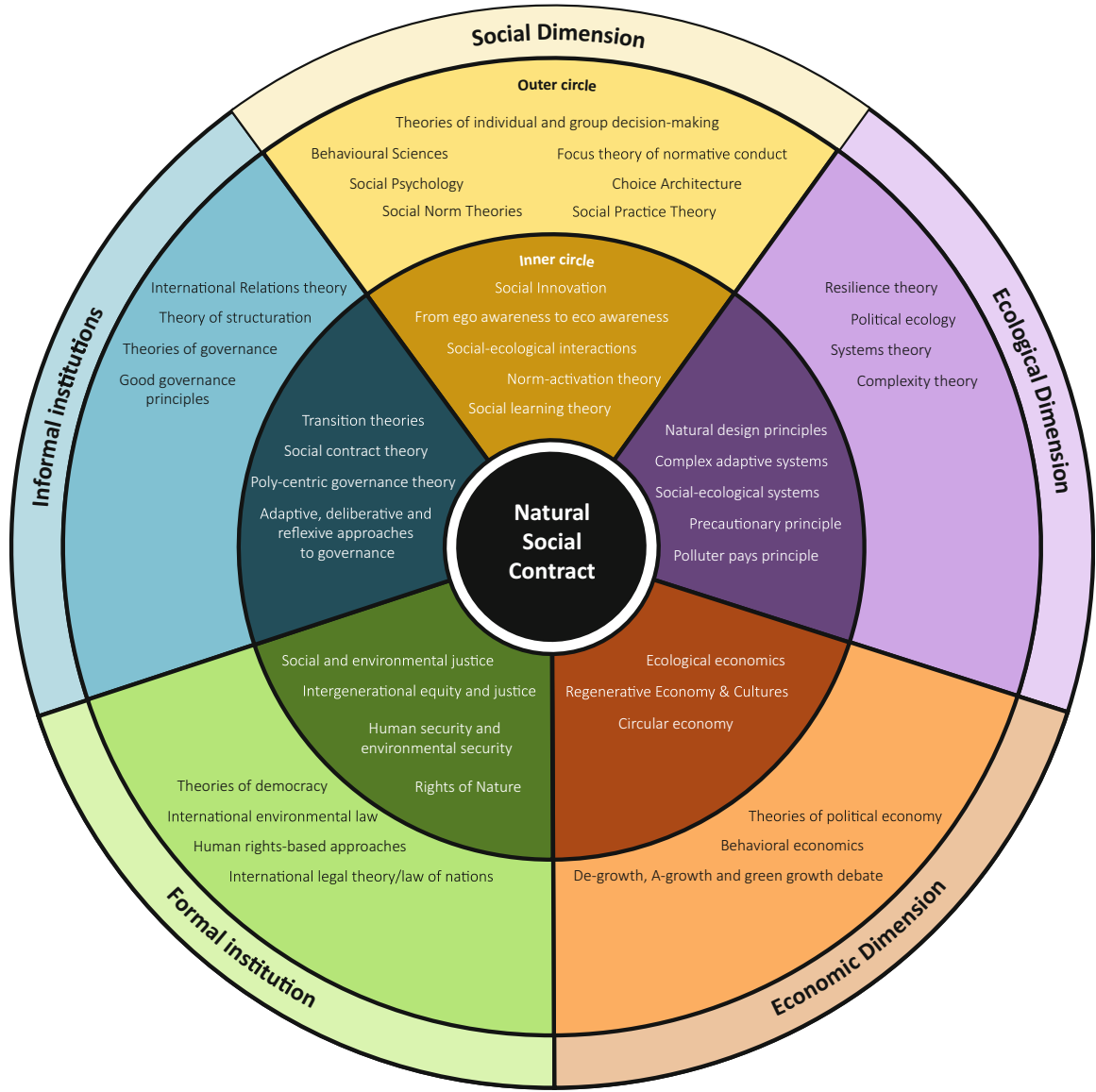

Fig. 3.4 Theoretical and open framework for a Natural Social Contract. The inner circle represents the theoretical core, and the outer circle represents the theoretical context. A clear delineation between dimensions is not possible, given the broad scope and overlap of some of the theories mentioned, while the positioning of a theory or concept in one dimension is sometimes artificial (for the purpose of visualization), given its relevance for other dimensions

This section concludes with an overview of design principles for a Natural Social Contract (see Table 3.3), which is a summary of Sect. 3.8 shaped as a course of action and is intended to help readers to grasp the core rationale of this book.

\section{Social Dimension}

Relevant for a Natural Social Contract is an explicit emphasis on a human being's natural state as a social animal living in families, as a member of a group, community, collective, organization, or company. Human life is group life (Chambers 
2018), regardless of whether these groups are large or small. In order to pursue selfpreservation and higher levels of well-being, people depend on group life, and thus reciprocity with their social and natural environment and related stewardship. Within this context, 'sharing' is an important evolutionary trait of humans. 'Shared efforts allowed our ancestors to band together to hunt, farm, and create shelter, and reciprocal forms of altruism arose naturally from repeated interactions in such collective groups' (cf. Agyeman and McLaren 2017). This sociological aspect of a Natural Social Contract is diametrically opposed to the individualistic nature of the 'Homo Economicus' (more information below) in a market-based neoliberal society in which citizens have been turned into consumers and customers. But customers behave differently from citizens, since customers demand what they have paid for but feel no duty to the community or natural environment. 'The human evolutionary trait of sharing has largely faded in capitalist societies, due to commercialization of the public realm, rapid economic and technological change, and the rise of competitive individualism' (ibid.). In a Natural Social Contract, however, all individuals are considered to be part of the community in some specific way, in varying degrees and often in diverse roles. If you ask people what guiding principles they find important in life, helping others and protecting the environment come out strongest (at least in an analysis of ca 44,000 responses from people representing 22 European countries and Israel (Bouman and Steg 2019). In Table 3.3 I provide an overview of several important aspects of human nature that could be re-invigorated through a Natural Social Contract.

With regard to people's reciprocity with their social and natural environment I make a distinction between 'social' and 'natural' environment. People's reciprocity with their social environment depends on solidarity, togetherness, mutual understanding, mutual trust, clear communication and, depending on which (collective or social) goal to achieve, it requires collective action and effective cooperation (see Sect. 4.9). Society cannot rely on the market or state alone for solutions to collective problems, nor leave it to individual responsibility, so the power of collective action deserves special attention. Society could be reorganized to allow for more problem solving at the community level (the subsidiarity principle) and by forming new coalitions in horizontal innovation networks. This will require research into socialecological interactions and interdependencies between stakeholders in complex change processes around nature, agriculture, land use, housing, mobility, and environmental issues and related policies (Aarts 2018). Research shows that 'people are good group problem solvers even if they are poor solitary truth seekers' (cf. Chambers 2018). Within this context, psychological and political science research shows that certain contexts motivate people to be reasonable, benevolent, and cooperative (Mendelberg 2002; Mercier and Landemore 2012; Chambers 2018; Dryzek et al. 2019). For example, small face-to-face group discussions can encourage individuals' cooperation (von Borgstede et al. 2013) and benevolent decisions (Mendelberg 2002). Within this context, people intend to engage more with environmental protection when they believe that future societies at risk of climate change will be more benevolent (Bain et al. 2013). People's reciprocity with their natural environment could be related to one's engagement in environmental issues 
Table 3.3 Aspects of human nature that could be re-invigorated through a Natural Social Contract

\begin{tabular}{l} 
Aspect of human nature \\
\hline Human life is group life
\end{tabular}
Explanation

Humans flourish when living in families, and as a member of a group, community, collective, organisation, or company. Increasing levels of emotional, social, and psychological well-being result from participation in social relations (Keyes 2002; Fredrickson and Losada 2005; Snyder et al. 2011). To pursue self-preservation and higher levels of well-being, people depend on group life and reciprocity with their social and natural environments and related stewardship. The individualistic nature of capitalist societies conflicts with this important aspect of human nature. Instead, society could reorganize to nourish social cohesion, collective action, and problem solving at the community level while recognizing that some problems require the governance of social and political issues at the most appropriate level (i.e. the subsidiarity principle) and often requires multilevel governance. For example, the COVID-19 pandemic presents a societal challenge that requires more centralized and international coordination and crisis management.

Sharing $\quad$ 'Sharing' is an important evolutionary trait of humans. However, sharing has largely faded in capitalist societies and related economic systems where individualism, profit, and private property have superseded our relationship with each other and nature. In particular, the trait of sharing became skewed due to commercialisation of the public realm, rapid economic and technological change, and the rise of competitive individualism (Agyeman and McLaren 2017). In a Natural Social Contract, the human trait of sharing could be reinvigorated in the form of a sharing economy as well as in a circular and regenerative economy (see Sects. 3.3 and 3.4, and 'Economic dimension') and by co-management of the commons (see Sect. 4.3): natural or cultural resources available to all members of a group or society. This includes shared fishing waters, forests, agricultural land, and urban commons, as well as sources of information (e.g. Wikipedia), knowledge and culture.

Individual and collective Humans possess a unique and unlimited ability to learn, gain new learning skills, and adapt to new environments and circumstances. Collective learning processes based on social relationships and networks are important for coping with uncertainty, enabling change, and developing the knowledge and ability to respond to new insights and developments (See Sect. 4.7 for more information on collective learning).

The power of imagination The ability to form mental pictures or ideas in the minds of people is a powerful tool that supports intrinsic motivation, individual and collective learning, problem-solving, co-creation, and innovation. As Albert Einstein said, 'Imagination is more important than knowledge. For knowledge is limited, whereas imagination embraces the entire world, stimulating progress, giving birth to evolution'. See Sect. 4.11 for more information on co-creation.

Storytelling and narratives of change
Storytelling is the oldest way to share knowledge and ideas. From the oral tradition of ancient people to the written word and now in the digital age, it is stories that engage and compel us to understand new phenomena. When combining the strengths of stories-for instance about sustainability heroes — with that of system's thinking 
Table 3.3 (continued)

\begin{tabular}{l|l}
\hline Aspect of human nature & Explanation \\
\hline & $\begin{array}{l}\text { it provides a powerful approach for transformative learning (e.g. see } \\
\text { Tyler and Swartz 2012), and the application of complexity thinking } \\
\text { in all social-ecological systems. This combination of storytelling } \\
\text { and systems thinking in order to facilitate transformative learning } \\
\text { and institutional change is known in literature as 'Narratives of } \\
\text { Change' (Krauß et al. 2018; Wittmayer et al. 2019). }\end{array}$ \\
\hline $\begin{array}{l}\text { The art of deliberate co- } \\
\text { creation }\end{array}$ & $\begin{array}{l}\text { Through the manifestation and sharing of ideas in social networks, } \\
\text { humans command a unique trait for co-creating knowledge and } \\
\text { advancing solutions. Co-creation involves collective problem } \\
\text { solving with multiple parties and where multiple parties recognize } \\
\text { mutual dependency and the importance of finding common ground, } \\
\text { shared values, and mutually accepted solutions (see Sect. 4.11). } \\
\text { Again, the power of imagination is important for co-creation when } \\
\text { manifested in a tangible and joint vision based on a shared future. } \\
\text { Such cooperation helps identify and create shared and common } \\
\text { values during the co-creation trajectory, which in turn strengthens } \\
\text { the bonds of actor coalitions (see Sect. 4.11). }\end{array}$ \\
\hline
\end{tabular}
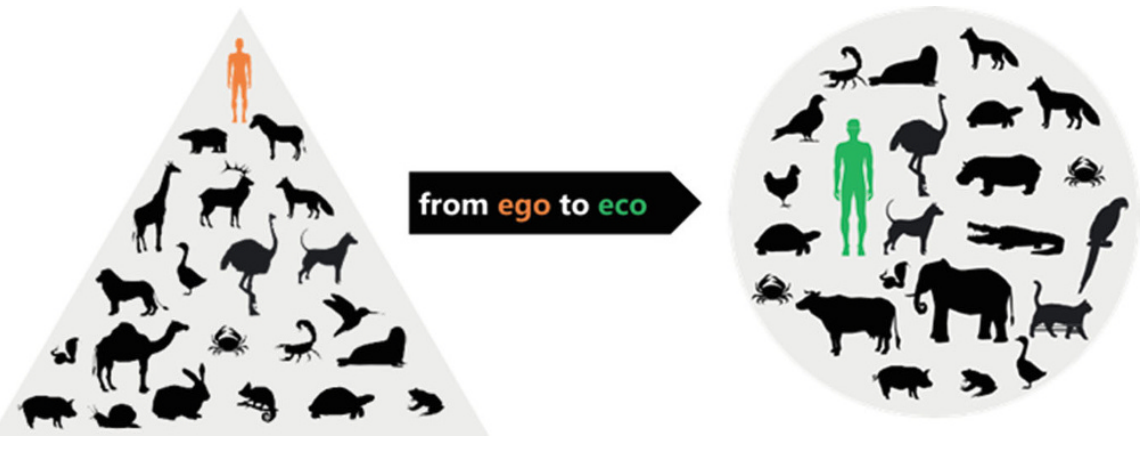

Fig. 3.5 From ego awareness to eco-awareness (Edited figure, based on Scharmer and Kaufer 2013)

(e.g. through membership of a civil society organization or as an employee of an organization or company working on sustainability issues), or participation in the joint and sustainable management of public commons (see Sect. 4.4), or a deliberate decision for a sustainable lifestyle in one's household, for example, to opt for renewable energy, sustainable housing, sustainable food consumption, to limit one's carbon-based travelling, etc.

At the individual level, the sustainability transition is a period in which people start to look at their own lives, their lifestyles, and the consequences with a new set of eyes. This process is also known as a transition from ego awareness to eco-awareness (Scharmer and Kaufer 2013), as shown in Fig. 3.5. Similar to a global citizen or cosmopolitan-someone who feels involved in the world and is actively committed to making the world a better and safer place-the sustainability 
transition requires a rethink of one's citizenship, which could involve a behavioural change towards a more sustainable lifestyle or participating in collective action for sustainability. This could translate directly into one's voting behaviour or encourage more sustainable consumption of products (e.g. sustainable food, less meat, recycled materials, renewable energy) and services (e.g. shared or green mobility, circularity, green investments, support for local food producers and short food chains, or participation in community-supported agriculture). 'The role of residents might shift from receiving services and bearing rights to becoming more active in their immediate living environment and being subject to duties' (cf. Wittmayer et al. 2017). More in general, it involves a rethink of one's relation with other people and with nature, changing one's behaviour to increase the solidarity and reciprocity with one's social and natural environment and related stewardship. A popular course of action and 'leitmotiv' for global citizenship is 'think global, act local', while the sustainability transition is expected to bring about a growing number of 'Green Cosmopolitans', seeking options for low carbon travelling, more sustainable consumption, cleaner technologies, and collective action for sustainability. In addition, citizen science, in particular for biodiversity monitoring, is becoming increasingly popular (Sect. 4.10). 'As responsible citizens of planet earth, we can actively participate in the co-creation of actionable knowledge and solutions' (cf. Santha 2020).

The transition from ego- to eco-awareness and related behaviour is also known in literature as a transformational change in humanity from the 'Homo Economicus' to the 'Homo Ecologicus' (Dryzek 1996; Bosselmann 2004; Becker 2006; Cecchi 2013). The 'Homo Economicus' is defined as a rational person who pursues wealth for his own self-interest and was first mentioned by John Stuart Mill in the nineteenth century. In economic theory it is a model of human behaviour that assumes that people will make choices in their own self-interest. The assumption of rationalityalso called the theory of rational behaviour-is primarily a simplification that economists make in order to create a useful model of human decision-making. Modern behavioural economists have disputed this theory, noting that human beings are actually irrational in their decision-making. Likewise, the concept of 'Homo Economicus' has received substantial criticism from other disciplines, either because of its misunderstanding of how social agents operate (Bourdieu 2005), and taking rationality of individual behaviour as the unquestioned starting point of economic analysis (Foley 1998), or because of the limited empirical outputs of rational choice theory (Green and Shapiro 1996). The 'Homo Ecologicus' provides a different model of human behaviour, which is closer to its natural behaviour, and provides a response to many of the above critics, in particular by zooming in on a human being's relationship (i) with itself, (ii) the community, and (iii) nature (Becker 2006). The 'Homo Ecologicus' turns out to be inescapably social, unlike 'homo economicus' (cf. Dryzek 1996). In Henryk Skolimowski's ecological humanism, the concept is used to emphasize an equal position between humans and nature (Fios and Arivia 2018). As such, the concept of 'Homo Ecologicus' aligns with criticism on anthropocentrism by modern philosophers such as Bruno Latour, Henk Manschot, and Harry Kunneman, who argue for a new relationship with the Earth and other living beings. 


\section{Nature Connects}

"According to a series of field studies conducted by Kuo and Coley at the Human-Environment Research Lab, time spent in nature connects us to each other and the larger world. Another study at the University of Illinois suggests that residents in Chicago public housing who had trees and green space around their building reported knowing more people, having stronger feelings of unity with neighbors, being more concerned with helping and supporting each other, and having stronger feelings of belonging than tenants in buildings without trees. In addition to this greater sense of community, they had a reduced risk of street crime, lower levels of violence and aggression between domestic partners, and a better capacity to cope with life's demands, especially the stresses of living in poverty.

This experience of connection may be explained by studies that used fMRI to measure brain activity. When participants viewed nature scenes, the parts of the brain associated with empathy and love lit up, but when they viewed urban scenes, the parts of the brain associated with fear and anxiety were activated. It appears as though nature inspires feelings that connect us to each other and our environment."

Text from: www.takingcharge.csh.umn.edu/how-does-nature-impact-ourwell-being, retrieved on 1-10-2020.

Literature on positive psychology provides valuable insights on Human Flourishing, an approach aimed at increasing levels of emotional, social, and psychological well-being, due to participation in social relations (Keyes 2002; Fredrickson and Losada 2005; Snyder et al. 2011). The concept of Human Flourishing has many applications to civic duty and social engagement. Keyes (2002) shows that most people are more concerned with personal achievements than social relationships, but that this does not necessarily improve their well-being, so Keyes argues that children and adults should be encouraged to participate socially, because it improves the feeling of well-being and fulfilment. Could this be the case for humans in relation to nature as well? Throughout history, nature has had a leading role as a source of inspiration for musicians, visual artists, and scientists and will always be a driving force of creative inspiration. Being in nature, or even viewing scenes of nature, reduces anger, fear, and stress and increases pleasant feelings (Mitchell 2013; Russell et al. 2013; Sandifer et al. 2015) and could even reduce mortality (White et al. 2019). Various studies provide evidence for the positive impacts of human's interaction with nature (see text box 'Nature Connects' for an illustration).

Literature on social psychology provides valuable insights on norm interventions with regard to sustainable behaviour. For instance, Schwartz's norm-activation theory (Schwartz 1977; Schwartz and Howard 1981) is a model that explains altruistic and environmentally friendly behaviour. Other relevant social norm theories include Festinger's (1954) social comparison theory, Bandura's (1977) social learning theory (see Sect. 4.8), and Cialdini and colleagues' (1990) focus theory of normative conduct. An increasing number of studies is focusing on norm 
interventions with regard to sustainable behaviour (De Leeuw et al. 2015; Sparkman and Walton 2017; Thomas et al. 2017; Manomaivibool et al. 2016; Stöckli et al. 2018), including studies that integrate the Norm Activation Model (NAM) and Theory of Planned Behaviour (TBP) to understand sustainable behaviour, for example, in transport (Liu et al. 2017) and food sustainability (Onwezen et al. 2013). The theory of planned behaviour, with its origins in behavioural sciences, suggests that 'important actions are intentional and that the intention to act in a certain way is the immediate antecedent and cause of the behaviour' (cf. Ajzen 1991).

Social practice theory suggests that 'group behaviour is shaped by a combination of cultural norms and habits, rules and regulations, modes of provision, and infrastructures that together determine the ways in which people behave' (cf. Strengers and Maller 2014). This is particularly significant in the context of governing processes of change towards a sustainable society (ibid.). Norms and values that are central to a Natural Social Contract are discussed under 'Institutional Dimension' in this section. Within the social dimension of a Natural Social Contract, there are various aspects of human nature that could be re-invigorated (see Table 3.3), including storytelling and narratives of change. Storytelling is the oldest way to share knowledge and ideas. From the oral tradition of ancient people to the written word and now in the digital age, it is stories that engage and compel us to understand new phenomena. When combining the strengths of stories-for instance about sustainability heroes-with that of system's thinking it provides a powerful approach for transformative learning (e.g. see Tyler and Swartz 2012), and the application of complexity thinking in all social-ecological systems. This combination of storytelling and system's thinking in order to facilitate transformative learning and institutional change is known in literature as 'Narratives of Change' (Krauß et al. 2018; Wittmayer et al. 2019).

Beyond the individual or citizen level, a transformation towards a Natural Social Contract assumes a change in behaviour and shifting roles for all societal actors. A social contract is an empty shell without participation in all layers of society. It requires a rethink of how each actor could contribute to the sustainability transition. For example, traditional banks as an institution are changing towards banking as a service adjusted to digital innovation, decentralized and sustainable production and consumption (Ryszawska 2018). Pension funds, with USD 28 trillion in assets (OECD 2011), along with other institutional investors, have an important role to play in financing the sustainability transition. Businesses have a decisive role to play in the transition from linear to circular business models. Civil society could play a number of roles in sustainability transitions beyond civil advocacy (Frantzeskaki et al. 2016), while 'governments are searching for different relationships between governments, institutions, and citizens, from active financial commitment linked with targets, and moving from controlling and containing to facilitating and supporting' (cf. Wittmayer et al. 2017). Higher education must prepare students for their future and educate them to think across sectoral boundaries and favour transdisciplinary approaches, which will require new knowledge and skills. This will address the grand societal challenges such as climate change mitigation and adaptation, circularity, urban health, citizen participation, food transition, and the energy transition (Sect. 7.5). 


\section{Ecological Dimension}

A Natural Social Contract explicitly emphasizes the natural position of humankind and society within a larger ecosystem, that of planet Earth. All life on earth is interconnected, interdependent, and subject to the same set of circumstances (e.g. sunlight, water, gravity, cyclical processes, complex adaptive systems, and non-linear feedback loops). Earth is the whole, within which humans are subservient (though impactful) parts. Hence, in a Natural Social Contract, society is viewed as a social-ecological system (SES), in which an ecological system is intricately linked with and affected by one or more social systems. In the past two decades, the concept of social-ecological systems (SES) has become central to an increasingly widespread international discourse on human-nature interactions (Berkes et al. 2000; Anderies et al. 2004; Olsson and Galaz 2012; Becker 2012; Skandrani 2016; Rissman and Gillon 2017, and others). Olsson and Galaz (2012) argue that only addressing the social dimension will not be sufficient to guide society towards sustainable outcomes. A societal transformation towards sustainability requires improving society's capacity to learn from, respond to, and manage environmental feedback from dynamic ecosystems (ibid.). For example, 'a systemic shift to biofuels might slow climate change, but lead to destructive land use change and biodiversity loss (Grau and Aide 2008). This in turn can lead to further ecological degradation, regime shifts, and lock-in traps in social-ecological systems that are difficult to get out of' (cf. Olsson and Galaz 2012).

Within the context of the sustainability transition, design lessons taught by nature, such as adaptive capacity, resilience, resource efficiency, circularity, selforganization, and the networked relationship between all organisms, deserve special attention (see Sect. 4.4). The similarities between well-functioning social and ecological systems are very large, but people have lost sight of some basic principles. In a healthy, mature ecosystem nothing is wasted, with full circularity of energy and matter, just to mention one thing. Could this be an example for a wasteless and circular society? The Cradle to Cradle movement and the ongoing transition to circular and regenerative economies and cultures make grateful use of these insights from ecology. Redesigned economics based on ecology, such as in Circular Economy and Regenerative Economy, will play a central role in developing a Natural Social Contract, at least from an economic perspective (see Sect. 3.3).

"A watershed includes all the humans, plants and animals who live in it, and all the things we have added to it such as buildings and roads. Everything we do affects our watershed-from washing clothes and growing food to mining, commercial farming, and building roads or dams. The reverse is also true: our watershed affects everything we do, by determining what kinds of plants we can grow, the number and kinds of animals that live there, and how many people and livestock can be sustainably supported by the land. One important

(continued) 
truth about watersheds is that we all live downstream from someone, and upstream from someone else. Anything dumped on the ground in the watershed can end up in its rivers, lakes or wetlands. And anything released to the air can come down again, nearby or thousands of miles away. We are all connected through watersheds. Watersheds do not respect political or administrative boundaries, and in fact can encompass several cultural, national and economic boundaries."

Text from www.internationalrivers.org, retrieved on 13-4-2020.

Valuable lessons can be drawn from societal transformations where insights from nature and principles of nature (see Sect. 4.4) have already led to paradigm shifts towards sustainability. For example, the water management regimes in low-lying countries such as the Netherlands and Vietnam have seen a paradigm shift in the past decades from the 'fight against water' towards 'living with water', by translating key lessons from ecology, in particular from resilience theory and adaptive management, into spatial planning for river basin management. For instance, the authorities have substantially improved the buffering capacity and resilience for peak discharges in the Rhine and Mekong river basins by undoing land reclamation and giving it back to nature and reconnecting the main rivers with wetlands, creating green bypasses, and broadening of floodplains by dyke replacements (Huntjens et al. 2011a, b, 2018). This paradigm shift in water management became possible once planners and engineers started to look at the rivers from an ecological point of view, in which land and water are linked in a natural system called a catchment, drainage basin, or watershed (see text box). The insight that a river basin can only become resilient and healthy through a basin management approach, and in case of the Rhine river basin and Mekong rivers basins thus requiring international cooperation, prompted the establishment of the Rhine and Mekong River Commissions and served as examples for European water policies and river basin management worldwide ever since (Heldt et al. 2017; Van Diep et al. 2007). Such a river basin management (RBM) approach is not a blueprint though and requires adaptation to the different socioeconomic, cultural, political, and biophysical contexts of the implementing countries.

The above examples explain why the concept of biomimicry (Sect. 4.4) has increased in popularity, as has, more recently, the interest in biomimicry in the context of social innovation, with the aim of creating products, processes and policies that are well-adapted to life on earth in the long term (Benyus 1997; Biomimicry 3.8 2013; Fullerton 2015; Wahl 2016). Within a Natural Social Contract, biomimicry should not be taken as an 'imitation' of life as much as a 'return' to natural, sustainable behaviour by humankind as a component of a greater ecosystem, that of planet earth. However sad this observation may be, the concept of biomimicry alone confirms that humankind lost its way at some point and stopped seeing itself as something 'natural', to the point that we are now forced to mimic nature for the purposes of self-preservation, increasing well-being and to safeguard the liveability 
of the planet for future generations. That is why I would argue that a Natural Social Contract, and the related process of Transformative Social-Ecological Innovation (TSEI), does not constitute mimicking nature, but rather constitutes a return to our origins. In essence, it means moving forward by looking backward. A Natural Social Contract determines the structure and functioning of a sustainable, healthy, and just society, in particular based on design lessons taught by nature. When combining these insights from nature and principles of nature (see Sect. 4.4) with the lessons learned from modernization and civilization processes and social contract theory, in particular humanity's quest for security and justice for all, it provides a logical and powerful combination for establishing a Natural Social Contract.

\section{Economic Dimension}

From an economic perspective, a Natural Social Contract reserves a central place for Circular, Regenerative, and Sharing/Collaborative Economies, which are forms of alternative economies that closely resemble natural human behaviour (see social dimension above, in particular on 'Homo Ecologicus') and natural design principles (Sect. 4.4 on biomimicry).

A Sharing/Collaborative Economy departs from the human evolutionary trait of sharing, which has largely broken down in capitalist societies (Agyeman and McLaren 2017), mainly due to the commercialization of the public realm, rapid economic and technological change, and the rise of competitive individualism (ibid.). In a Sharing or Collaborative Economy 'access' to goods and services is more important than 'ownership' of goods (Belk 2014; Barbu et al. 2018). A common premise is that when information about goods is shared (typically via an online marketplace), the value of those goods may increase for the business, for individuals, for the community, and for society in general. In this vein, Mason (2016) argues for more cooperative schemes of free exchange—a 'sharing' economy to replace a predatory one-and more collective ownership as well. For example, carsharing is part of a larger trend of shared mobility, which is different from car rental in that the owners of the cars are often private individuals themselves, and the carsharing facilitator is generally distinct from the car owner. In particular, the transition to a Sharing or Collaborative Economy requires a change from traditional market behaviour to collaborative consumption models, in which resources are used more efficiently and sustainably. This economic model is therefore part of a broader transition to a circular and regenerative economy and offers business models that are compatible with it (Barbu et al. 2018).

Similar to the alignment with natural human behaviour, as in the case of a Sharing or Collaborative Economy, a Natural Social Contract underscores the importance of economic design based on, or inspired by, lessons taught by nature and natural design principles (see Sect. 4.4). In particular design lessons taught by healthy and mature ecosystems deserve special attention, such as adaptive capacity and resilience, resource efficiency, and circularity. Circular Economy and Regenerative Economy are examples of economic design based on ecology, where nature shows 
how circularity is usually organized at the lowest possible level. Likewise, circularity needs to be understood as a property of a system, such as the mobility system of a city, rather than a property of an individual product or service, for instance, a car or a carsharing service (Konietzko et al. 2020). These new economic models promise to organize different forms of sustainability at different levels, where the prevention of waste and the valuation and revaluation of all matter and resources are important starting points. A large part of our clothing, furniture, electronics, and our food ends up at a dumping ground for waste or is incinerated, while it still contains a lot of valuable raw materials. Much more can be done, but getting there requires technological and social innovation, including organizational and institutional innovation. The ratio between the impact of technology and social innovation for realizing a circular economy is estimated at 25:75 (Jonker et al. 2018).

Within the school of Ecological Economics, which originated in the 1980s, the economy is treated as a subsystem of Earth's larger ecosystem and addresses the interdependence and coevolution of human economies and natural ecosystems, both intertemporally and spatially (Xepapadeas 2008; Van den Bergh 2001). The literature on Ecological Economics emphasizes that the natural world has a limited carrying capacity and that its resources are running out. Ecological economists assume 'that growth is not a given, and that population growth, inequalities, and the decline of cheap and abundant fossil fuels, which spurred the unprecedented growth of the global economy over the past century, mean that the limits to growth are either being reached or will be reached in the very near future' (cf. Caradonna et al. 2015). 'Since the destruction of important environmental resources could be catastrophic and practically irreversible, ecological economists are inclined to justify cautionary measures based on the precautionary principle' (cf. Costanza 1989).

By contrast, 'Ecomodernism' is a school of thought 'that emphasizes the roles of technology and economic growth in meeting the world's social, economic, and ecological challenges' (cf. Caradonna et al. 2015). The Ecomodernist Manifesto (2015) rejects the idea 'that human societies must harmonize with nature to avoid economic and ecological collapse. Instead, it argues for more reliance on technologies, from nuclear power to carbon capture and storage. Many ecomodernists ridicule the idea of limits to growth, arguing that technology will always find a way to overcome those limits. For instance, they believe we can feed the world with more intensive agriculture, the combination of hybrid seeds, highintensity fertilizers, precision agriculture, and making crops more productive with genetically modified organisms (GMOs). Basically, keep doing what we have been doing but make it cleaner' (ibid.).

Conversely, ecological economists consider industrial agriculture as the problem causing environmental degradation. For energy supply, 'they propose renewable energy sources (e.g. wind and solar), instead of nuclear power, since the latter will lead to long-term storage nightmares and present-day environmental hazards (e.g. see Chernobyl and Fukushima). For carbon capture they propose planting trees instead of technical solutions. For feeding the world, they would like to see a radically different form of agriculture (e.g. based on organic agriculture, permaculture, and food forests, which also reduce the output of carbon), one that does not 
depopulate the countryside, one that mimics natural ecosystems and grows lots of types of crops' (cf. Johnson 2018). It requires more work than industrial solutions, but would create more jobs and vital rural communities. 'Ecological economics shares several of its perspectives with feminist economics, including the focus on sustainability, nature, justice, and care values' (cf. Aslaksen et al. 2014).

While Ecomodernists value individual liberty more, Ecological Economists place more value on communities, but there is no law of physics that says you cannot have both (Mann 2018). There is an obvious middle ground, and more attention should be devoted to a mix of solutions and to bridge the divide between both camps. For example, for developing climate-resilient coastal areas and cities (see Chap. 7), it makes perfect sense to use a portfolio approach of desalination technologies, breeding of drought or salt-tolerant species, renewable energy, and other technological solutions, in combination with reforestation, circular and regenerative agriculture, and community-based approaches, thus combining the best of both worlds. For a regional and circular food system (see Chap. 6), it makes sense to combine both high-tech methods, such as vertical farming, robotization, artificial intelligence and information technologies, and low-tech methods, such as vegetable gardens, urban gardens, food forests, and regenerative agriculture. With a shared vision, part of these (future) production systems is high-tech, while the systems are in harmony with nature, with a fully transparent and zero-emission food chain, including food producers and consumers as co-owners of their own food system. Recently, interest in local food systems has skyrocketed (Pigford et al. 2018), centred around an approach in which citizens, farmers, and other stakeholders work together to create a sustainable, healthy, and predominantly local food system (see Chap. 6 for examples).

The majority of products and services in our current market-based economies leads to increasingly higher and hidden societal and ecological costs. Think of environmental and climate damage, damage to human and animal health, and underpayment of farmers and health workers, for instance. These costs are not included in the market price of the product or service. Making these costs visible and including these costs in the prices of products and services is an important avenue for creating a level playing field with more sustainable, healthy, and fair products and services. This is the essence of True Cost Accounting (TCA) or Full Cost Accounting (FCA), which represents a rapidly growing academic discipline (Negowetti 2016; Aspenson 2020), in particular in the food and clothing industry, focused on calculating the impact that products and services have on natural, human, and social capital-the so-called business externalities. Usually these impactspositive or negative-are not reflected in the prices paid by users/consumers. Hence, calculating true costs, based on the discounting of integral costs such as $\mathrm{CO}_{2}$, nitrogen, toxicity, or living wage, is an essential step in creating an economic model in which transparency, sustainability, health, and fair prices and incomes are central rather than high volume, low prices, and low incomes. With the vast majority of consumers usually opting to pay the lowest price, it prompts the food and clothing industry to adopt highly efficient, low-lost production methods. As a consequence, there is little incentive for actors in these production chains to invest in sustainability 
measures and translate those into cost price. This economic logic leads to a vicious circle and a race to the bottom. Hence, True Cost Accounting is an important intervention to break this vicious circle. In the coming decade, the incorporation of true prices into our economic systems will be an important systemic change towards a Natural Social Contact.

\section{Institutional Dimension}

By taking Calhoun's definition (2002) of institutions as 'deeply rooted patterns of social practices or norms that play an important role in how society is organized' it becomes evident that the institutional dimension has close ties with every dimension of a Natural Social Contract. A further distinction is made between formal institutions (those adopted through a formalized process, including the constitution, laws, and legislation) and informal institutions (those embedded in organizations or groups without a formalized process, including customary law, existing practices, norms, and culture).

There are relevant crossovers between the ecological dimension and the institutional dimension within a Natural Social Contract. Examples of institutional design based on ecology include governance approaches that are better capable of dealing with complexity and uncertainty, such as adaptive, deliberative, and reflexive governance (Sect. 4.7). Rather than considering complexity and uncertainty as difficult obstacles that must be controlled, mitigated, or ignored, these characteristics of social-ecological systems should be considered drivers of Transformative SocialEcological Innovation (TSEI). Other examples of ecological-institutional crossovers include the precautionary principle and polluter pays principle as important mechanisms for steering social-ecological systems towards sustainability. Furthermore, insights from the governance of the commons and the sustainable co-management of natural resources (e.g. fishing grounds, forests, and agricultural land) and cultural resources (e.g. sources of information, knowledge, and culture) are relevant for the institutional design of a Natural Social Contract (see Sect. 4.3).

A Natural Social Contract necessitates governance at a level of scale that does the most justice to the complexity of socio-ecological systems, for example, through polycentric governance (Sects. 4.3 and 4.6). Within this context, the principle of subsidiarity, one of the core principles of European Law, prescribes the governance of social and political issues at the most appropriate level. Section 3.10 provides examples for the development and implementation of a Natural Social Contract at various governance levels, ranging from the local to the national and international level. Within this context, adaptive governance of social-ecological systems generally involves polycentric institutional arrangements (see Sect. 4.3), 'which are nested quasi-autonomous decision-making units operating at multiple scales (Ostrom 1996; McGinnis 2000). They involve both local and higher organizational levels and aim to find a balance between decentralized and centralized control (Imperial 1999). The term multi-level governance is used to characterize the relationship between actors situated at different administrative and territorial levels. This creates layers of actors 
who interact with each other: (1) across different levels of government (vertical coordination); (2) among relevant actors at the same level (horizontal coordination at central or at subnational level); or (3) in a networked manner. This relationship exists regardless of the constitutional system (federal or unitary) and impacts the implementation of public policy responsibilities. Debates over "scaling" powers within multi-level governance have become widely discussed in several related academic sub-disciplines, including economic federalism (e.g. Oates 1998), political geography (e.g. Delaney and Leitner 1997), EU studies (Hooghe and Marks 2003; Bache et al. 2016; Hooghe et al. 2020), and international public policy (Young 2002). For example, conflicts over the appropriate "scale" (Young 2002) or institutional level of policymaking characterize multi-level governance' (cf. Huntjens 2011). In the past two decades, multi-level governance has become an important concept in climate change and environmental policies (e.g. see Di Gregorio et al. 2019; Hooghe et al. 2020) and is often used to capture the dynamics of EU cohesion policy (Bache et al. 2016).

Finally, on the topic of governance, many of the institutional arrangements relevant for a Natural Social Contract are reflected in Good Governance Principles, developed and adopted by the United Nations (UNESCAP 2009) and the Council of Europe (CoE 2008) among others, covering issues such as ethical conduct, rule of law, efficiency and effectiveness, transparency, sound financial management, and accountability. These principles are applicable to corporate, international, national, or local governance. It should be clear that good governance is an ideal which is difficult to achieve in its totality. Very few countries and societies have come close to achieving good governance in its totality (UNESCAP 2009).

Between the economic dimension and institutional dimension there is a variety of crossovers. As already mentioned under economic dimension, for realizing a circular economy it requires technological and social innovation (including organizational and institutional innovation) with a ratio of 25:75 (Jonker et al. 2018). Likewise, a number of institutional innovations have already been tested for realizing a sustainable, healthy, and predominantly local food system (see Chap. 6), such as Food Policy Councils (FPCs), as loci for practising food democracy (Sieveking 2019; Scherb et al. 2012; Gupta et al. 2018; Sussman and Bassarab 2017), communitysupported agriculture (CSA), as a sustainable alternative for industrial agriculture (Kondoh 2015; White 2020; Galt 2013), and Short food supply chains (SFSC), which aim 'to reconnect the two extremities of the food supply chain, reconcile producers with citizens, stimulate mutual trust, and establish a short chain based on common values on food, its origin and production method' (cf. SKIN 2020).

Taxation is a powerful tool for steering the behaviour of both producers and consumers. Taxation policy thus relates directly to a Natural Social Contract's economic and social dimension as described in this section, but certainly also to the institutional dimension. Several recent studies show that sustainability-oriented taxation is an effective tool for mitigating unsustainable and unhealthy behaviour, products and services, for instance, through carbon taxes (Krenek and Schratzenstaller 2016; Ulucak and Kassouri 2020). On top of that, fuel taxation may be a promising public health intervention for obesity prevention (Brown et al. 
2017), since it would become more expensive to use motorized vehicles, and instead encourages people to walk or take a bicycle more frequently. Tax revenues, in return, can be used to provide positive incentives for sustainable and healthy practices, behaviour, products, and services while helping to offset the costs of the sustainability transition, in a socially just manner. Likewise, taxation policy could play an important role in addressing growing inequality. Empirical studies show that inequality is increasing (Piketty 2013; Kremer and Maskin 2006). When labour is more heavily taxed than wealth, the rich are getting richer, while the poorer part of the population succumb to make ends meet (Scheve and Stasavage 2016). The tax on capital must therefore increase considerably, that on labour considerably down. Higher taxes from the rich would pay for programmes that improve the welfare of the poor through the government's expenditure policy. Hence, given its role in feeding budgets, distributing resources, and steering behaviours, taxation has a pivotal role in a societal transformation towards a Natural Social Contract.

Not surprisingly, there are close ties between the social and institutional dimensions in a Natural Social Contract, of which perhaps the most prominent include norms and values, which are either adopted in formal institutions or embedded in informal institutions.

Core values of a Natural Social Contract should be made explicit and discussed in any process of Transformative Social-Ecological Innovation and is often a necessary step in the process of creating shared value and multiple value creation (Sect. 4.8). The focus theory of normative conduct proposes, for example, 'that norms are important to the extent they are made salient at the time of action, such that individuals make behavioural decisions on the basis of normative considerations, rather than other considerations' (cf. Cialdini et al. 1990).

Common values in a Natural Social Contract could be context-specific to some extent, tuned to specific features of local geography, ecology, economies, and cultures, but also include a certain level of universality, especially when reasoning from a human being's natural state as a social animal living in families and thus requiring some level of collectivity, solidarity, mutual trust, and reciprocity. Chances of survival are larger when operating as a group, requiring clear communication and effective cooperation. Common values also appear when looking at general and historical patterns of civilization, modernization, and the human need for social order, security, and justice. Schwartz and Bilsky (1987) defined 'values' as 'conceptions of the desirable that influence the way people select action and evaluate events'. They hypothesized that 'universal values would relate to three different types of human need: biological needs, social coordination needs, and needs related to the welfare and survival of groups' (ibid.). The claim for universal values can be understood in two different ways. First, it could be that something has a universal value when everybody finds it valuable. Second, something could have universal value when all people have reason to believe it has value' (cf. Jahanbegloo 1991). 'When Mahatma Gandhi argued that non-violence is a universal value, he was arguing that all people have reason to value non-violence, not that all people currently value non-violence' (cf. Amartya Sen 1999, page 12). The same reasoning could be applied to values related to a Natural Social Contract, in which all people 
have reason to believe that solidarity and togetherness (as being central to group life), environmental protection, and the sustainable and joint management of shared resources, collective well-being, democracy, and justice are valuable and thus accepted as general principles for governing day to day life.

In the past few decades, values on the relationships between humans and nature are becoming more prominent and recognized in initiatives, policies, and laws around the world (Sect. 3.10). In particular, the Rights of Nature as a legal and jurisprudential theory, which describes inherent rights associated with ecosystems and species, deserves special attention. While twentieth and twenty-first century environmental laws do afford some level of protection to ecosystems and species, it is argued that such protections fail to stop, let alone reverse, overall environmental decline, because nature is by definition subordinated to anthropogenic and economic interests, rather than the well-being of non-humans and nature (Cullinan 2011; Berry 1999; Biggs et al. 2017; Borràs 2016). Thomas Berry (2006) proposed that society's laws should derive from the laws of nature, explaining that 'the universe is a communion of subjects, not a collection of objects'. Just as human rights are increasingly being recognized in law, advocates claim that nature's rights must also be recognized and incorporated into human ethics and laws. This claim is substantiated by the same ethic that justifies human rights, and that the survival of human beings depends on healthy ecosystems (Cullinan 2011; Berry 1999; Stone 1996; Nash 1989). An obvious challenge to the Rights of Nature is that neither Nature in general, nor particular species and ecosystems have the kind of agency required to exercise and defend their rights. Environmental law scholars therefore suggest appointing a custodian to represent the Rights of Nature while taking precautionary measures to avoid an overly anthropogenic representation by such a custodian. While not without obstacles, the inclusion of ecocentric theories in legal frameworks is an important avenue for a societal transformation towards a Natural Social Contract.

The Gallup Institute's World Values Survey indicates an ongoing paradigm shift towards eco-awareness and post-materialistic value sets. The rise of postmaterialist values is part of a broader set of cultural changes that tend to bring democratization (Inglehart 2017) and a transition from ego awareness to eco-awareness (Scharmer and Kaufer 2013). This trend is reflected in public opinion, policies, and laws around the world, including the following examples:

- The United Nations World Charter for Nature, adopted in 1982, announced five principles of conservation by which all human conduct affecting nature is to be guided and judged.

- The Earth Charter-an ethical framework for sustainable development published in 2000-reserves a central place for environmental protection, human rights, equitable human development, and peace and argues that these values are interdependent and indivisible.

- Several countries have recognized Rights of Nature in their legal frameworks and/or jurisprudence, e.g. in Uganda, Peru, Ecuador, Mexico, Colombia, India, Bangladesh, New Zealand, and communities in the USA. 
- Granting rights to rivers, e.g. the Whanganui River in New Zealand, the Yarra River in Australia, and the Ganges and Yamuna rivers in India.

- The Universal Declaration of Rights of Mother Earth, adopted by the World People's Conference on Climate Change and the Rights of Mother Earth, April 22, 2010 in Cochabamba, Bolivia.

- Intergenerational justice and equity, a range of immediate and effective mechanisms is proposed to safeguard the rights of future generations and protect them from the potential negative implications and harm caused by climate change and environmental degradation (Sect. 2.3).

- In many countries, public interest in animal welfare, animal rights, and plantbased diets has increased significantly (Grunert et al. 2018). The World Animal Protection (WAP) charity has successfully lobbied the United Nations to include language on animal welfare in two General Assembly Resolutions on agriculture and disaster risk reduction in 2013, but surprisingly, there is no mention of animal welfare in the UN Sustainable Development Goals adopted in 2015 (VisserenHamakers 2020).

Generally speaking, a Natural Social Contract reserves a central place for core values such as solidarity, togetherness, collective well-being (as being central to group life), democracy, equity, social and environmental justice, and social and environmental stewardship. The latter entails stewardship for, and reciprocity with, our social and natural environment, for example, through the sustainable co-management of natural resources (e.g. fishing grounds, forests, and agricultural land) and cultural resources (e.g. sources of information, knowledge, and culture). More specifically, a Natural Social Contract stresses the importance of values such as social and environmental stewardship. After all, everyone is part of a social and natural environment, and the environment is part of each of us. It is worth noting that values such as stewardship and solidarity have a prominent role in all world religions. For instance, many religions and denominations have various degrees of support for environmental stewardship, which is a theological belief that humans are responsible for taking care of the world, including all life (humans, animals, and nature). Another example comes from New Zealand, where the Maori term Kaitiaki is used for the concept of guardianship, for the sky, the sea, and the land. This concept has been adopted in New Zealand's legislation, allowing Maori communities to be appointed as guardians for a specific area.

The overall goal of a Natural Social Contract is to promote human and environmental security, social and environmental justice, and planetary health. This could be translated in a tangible vision of a sustainable, healthy, and just society where prosperity is broadly defined and fairly distributed, including the economic, ecological, and social dimensions of prosperity and sustainability, and with interventions designed to mitigate poverty, inequality, social exclusion, and environmental degradation. This vision must include gender equality, and interventions to ensure that women have the same prospects and opportunities as men, and interventions to protect the sick, the vulnerable, and minorities of all kinds. Such a tangible vision could serve as a vehicle to identify and create shared and common values during the 
process of Transformative Social-Ecological Innovation (TSEI). Agreement on these ethical and normative aspects is important for holding actor coalitions together during a transition process and could be achieved through deliberation on shared beliefs and values, shared discourses, common interests (Sect. 4.8), procedural justice (Sect. 4.9), and options for multiple value creation and mutual gains (Sect. 4.8).

Table 3.4 provides a summarized overview of this section in the form of design principles for a Natural Social Contract. This overview is shaped as a course of action and is intended to help readers to capture the core rationale of this book.

\subsection{TSEI-Framework for Understanding and Advancing the Process Towards a Natural Social Contract}

Social contract thinkers ask themselves how social and political order in society can be legitimized (Gabriels 2018). Although their opinions differ, Gabriels argues they all take the same three steps: 'First of all, they outline a baseline situation, a conflict situation that must be resolved by means of a contract. Secondly, contract thinkers present a procedure for agreeing on the content of the contract, which should offer various different solutions to a conflict situation. Thirdly, contract thinkers describe the results of the chosen procedure, i.e. the actual implementation of the contract'. In this section I introduce and propose a conceptual framework for Transformative Social-Ecological Innovation (see Fig. 3.6), with the purpose of providing a better understanding and advancing the process of developing and implementing a Natural Social Contract. In section I will follow the same three steps as described above by Gabriels (2018).

The baseline situation for a Natural Social Contract is outlined in Chaps. 1, 2, 3 and constitutes a complex set of security and justice problems that need to be resolved. In the previous chapters it becomes clear how the most comprehensive societal fault lines of our times are deeply intertwined and confronts us with challenges concerning the security as well as justice of our societies. Increasing wealth inequality, financial crises, ecological crisis, climate crisis, trade wars, migration issues, and even the Corona pandemic can be traced back to two common denominators. First, the schism between humans and nature, and the dominant anthropocentric world view that arose during the Enlightenment. Second, the capitalist economic logic, in particular the unsustainability of infinite economic growth in a finite world, and the belief in the infallibility of the free market, that arose after the Second World War. It left us with market-based societies that reserve a central place for individualism, materialism, privatization, short-termism, the free market, and a singular focus on profit and economic growth. In a market-based society citizens have been turned into customers and consumers and demand what they have paid for, but feel no duty to the community or environment. This led to decades of excessive production, consumption, and depletion of our natural resources and raw materials. The resulting loss of biodiversity and key ecosystem functions, environmental degradation, bio-industry, land, water, and air pollution, and fossil energy 
Table 3.4 Fundamentals and design principles for (a societal transformation towards) a Natural Social Contract

\begin{tabular}{|c|c|}
\hline Dimension & Fundamentals and design principles for a Natural Social Contract \\
\hline Social & $\begin{array}{l}\text { Rediscover or reinvigorate community: Human life is group life, and people are } \\
\text { woven into a web of dependencies, and are generally happier if they can take care } \\
\text { of each other and nature and know that they are being taken care of. Society could } \\
\text { be re-organized in such a way that problems can be solved at the most appropriate } \\
\text { level (the subsidiarity principle), while citizens should be involved as much as } \\
\text { possible in decisions about their own living environment }\end{array}$ \\
\hline
\end{tabular}

From 'Homo Economicus' to 'Homo Ecologicus': Aspires to

interconnect individual and community with social and natural environments » Move from ego- to eco-awareness and beyond individualism to social and environmental stewardship and solidarity

Human flourishing in a responsible way: Aims to increase levels of emotional, social, physical, and psychological well-being through our connections to and participation in our social and natural environments

Encourage and support collective and adaptive learning processes » Advance information management through participatory knowledge creation, transdisciplinary research, and a commitment to dealing with uncertainties, as well as reflexive monitoring, broad communication between stakeholders, open and shared information sources, and flexibility and openness to experimentation (e.g. in living labs)

Shaping group behaviour and social-ecological interactions: Governing processes of change towards a sustainable, healthy, and just society. This takes into account a combination of cultural norms and habits, rules and regulations, modes of provision, and infrastructures. See also 'Taxation' below

\begin{tabular}{l|l} 
Economic & Economy for human and planetary well-being, not for profit: This requires us
\end{tabular} to broadly define welfare, including the economic, ecological, and social aspects of prosperity

From linear economies (i.e. produce, use and dispose) towards local, circular, and regenerative economies and cultures: Designing economic models based on lessons from nature (e.g. circularity at the lowest possible level, short supply chains, local self-sufficiency in water, food, energy). This requires a transition from linear to circular business models characterized by collective and shared value creation

\section{Joint management of the commons instead of private ownership:}

Ensure sustainable co-management of natural resources (e.g. fishing grounds, forests, and agricultural land), urban commons, and cultural resources (e.g. sources of information, knowledge, and culture)

Sharing economy: Facilitating shared access to goods and services (e.g. through a community-based online platform) to improve efficiency, sustainability, and community values

Diversify financial resources: Apply a broad set of public and private financial instruments. This could include innovative and hybrid forms of banking and financing (e.g. revolving energy and sustainability funds)

True cost pricing: Making visible the hidden social and ecological costs in the price of products and services. This encourages the creation of a level playing field with more sustainable, healthy, and fair products and services

Ecological Navigating complexity \& embracing systems thinking: Systems thinking sees life in continuous motion and recognizes that the larger picture is rarely static but rather almost always a web of factors that interact to create patterns and change 
Table 3.4 (continued)

\begin{tabular}{|c|c|}
\hline Dimension & Fundamentals and design principles for a Natural Social Contract \\
\hline & $\begin{array}{l}\text { over time. Adopting a systems-based approach helps identify synergies and trade- } \\
\text { offs that move beyond linear to more circular and inclusive systems }\end{array}$ \\
\hline & $\begin{array}{l}\text { Governing society as a social-ecological system: Earth is the whole in which } \\
\text { humans are subservient (but impactful) actors. We must design new ways to } \\
\text { inhabit and cultivate our planet to keep it healthy for future generations } \\
\text { (e.g. through renewable energy, sustainable agriculture and water management, } \\
\text { circular and regenerative economies, environmental protection, polluter pays } \\
\text { principle, precautionary principle) }\end{array}$ \\
\hline & $\begin{array}{l}\text { Accept nature as a teacher, not as an enemy: Learn from, respond to, and } \\
\text { manage environmental feedback from dynamic ecosystems. Economic and } \\
\text { institutional design based on lessons learned from nature (in particular sustainable, } \\
\text { healthy, and mature ecosystems). This includes adaptive capacity, resilience, } \\
\text { resource efficiency, circularity, self-organization, and the interconnected } \\
\text { relationship between all organisms }\end{array}$ \\
\hline & $\begin{array}{l}\text { Work with Mother Nature, not against Her: Urban and rural landscapes where } \\
\text { ecology and economy encourage equilibrium that produce and protect at the same } \\
\text { time (see examples of eco-cities, sponge cities, and circular and nature-inclusive } \\
\text { agriculture in this book) }\end{array}$ \\
\hline Institutional & $\begin{array}{l}\text { Invest in inclusive and deliberative local democracy and polycentric } \\
\text { governance: (1) Strengthening inclusive procedures to broaden legitimacy of } \\
\text { decisions and actions, through stakeholder participation and involving all layers of } \\
\text { society; (2) deliberating shared beliefs and values, common interests, procedural } \\
\text { justice, and opportunities for multiple value creation and mutual gains; } \\
\text { (3) encouraging consensus and collective action based on reasonable and } \\
\text { evidence-based arguments where persuasion emphasizes mutual understanding } \\
\text { and compromise and supports a process that is inclusive, open, trusting, and } \\
\text { collective }\end{array}$ \\
\hline
\end{tabular}

Adaptive, reflexive, and deliberative approaches to governance: Taking ambivalence, complexity, uncertainty, and distributed power into consideration in societal change. Governance, planning, and management at a level of scale that does the most justice to the complexity of social-ecological systems (subsidiarity principle)

Security and justice for all: Promote the equal and fair distribution of wealth instead of rising inequality, including equal and fair (re-)distribution of risks, costs, and benefits through the involvement and strengthening representation of marginalized and particularly vulnerable groups and stakeholders. Ensure that women have the same prospects and opportunities as men; and protect the sick, the vulnerable, and minorities of all kinds

Rule of Law and accountability: Recognize and incorporate human rights and the Rights of Nature into human ethics and laws. Adhere to the rule of law with regard to human and environmental security and justice while preventing and resolving conflicts through a variety of mechanisms (e.g. expanding access to justice and dispute resolution mechanisms)

Taxation: Mitigate unsustainable and unhealthy behaviour, products, and services through effective taxation policy (e.g. carbon tax). Tax revenues and tax rebates can offer positive incentives for sustainable and healthy practices, behaviour, products, and services. Additionally, taxation addresses growing inequality by enacting progressive tax policies on capital and lowering tax burdens on labour 


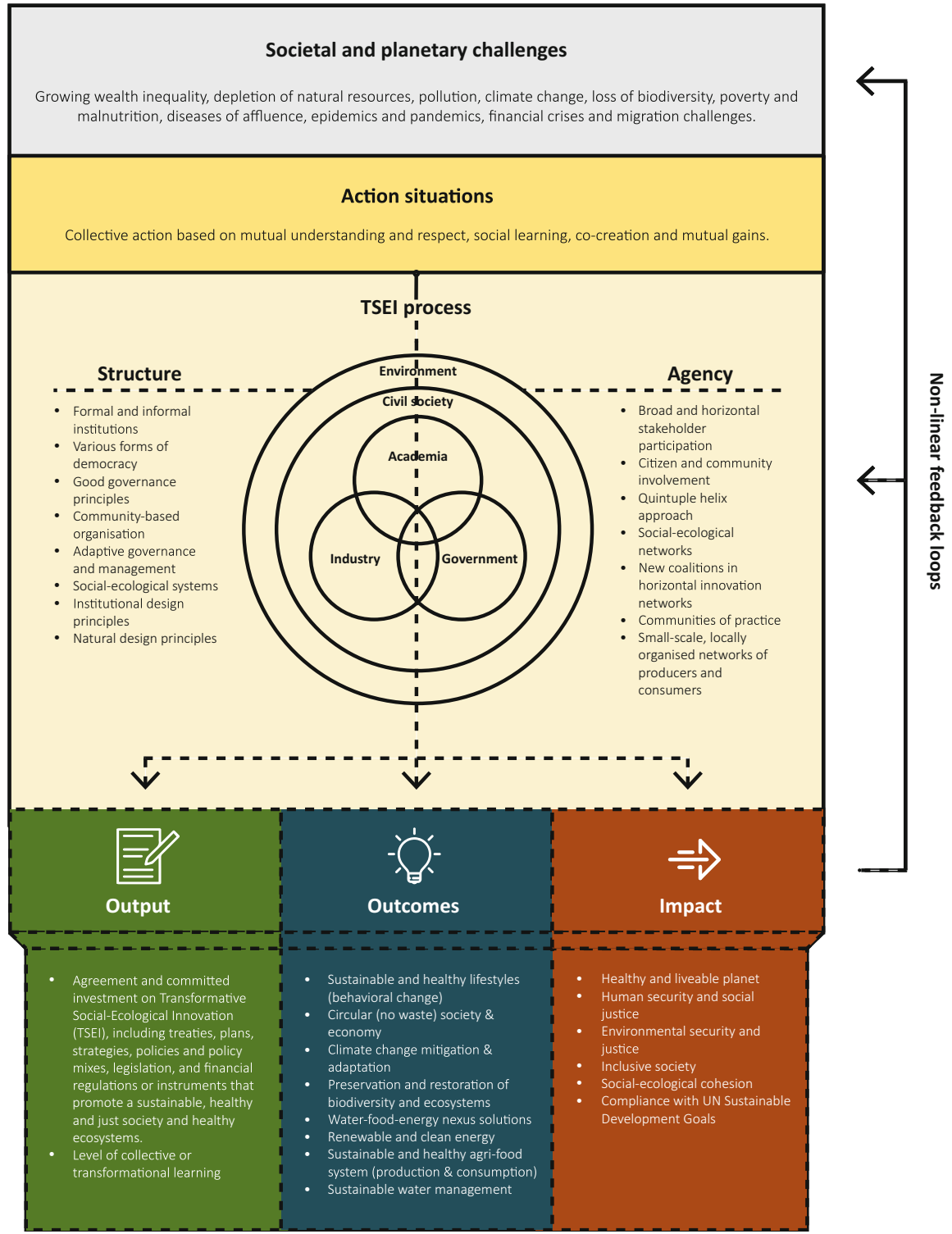

Fig. 3.6 Conceptual framework for Transformative Social-Ecological Innovation (TSEI)

consumption, for instance, show that the way we deal with nature is profoundly disturbed. We are now discovering that ecological vulnerability translates into economic and social vulnerability and a complex set of security and justice challenges. 
The procedure describes how an agreement about the contents of a social contract can be achieved. A social contract is not a formal contract of course, but something that is lived and practised. It is something that has to grow, but the mechanisms of its growth and interaction with existing orders are not well understood. The conceptual framework for Transformative Social-Ecological Innovation (TSEI) presented below is developed with the objective to provide a better understanding of the 'procedure' for realizing a Natural Social Contract (see Fig. 3.6, with more detail in Chaps. 4 and 5). In this book I emphatically replace the more formal term 'procedure' with 'process', since TSEI does not specify a blueprint, but encourages transformative processes tuned to the specific features of local geography, ecology, economies, and cultures.

The Transformative Social-Ecological Innovation (TSEI) framework presented in this book offers new ideas for unpacking and understanding institutional change across sectors and disciplines and at different levels of governance. To this end, it identifies intervention points and helps to formulate sustainable solutions that can include different views, as well as changing and competing needs. Overall, the concept of TSEI encourages public officials, business leaders, and the greater public to think more broadly about how society can rethink cooperation to address humankind's greatest challenges.

Transformative Social-Ecological Innovation (TSEI) is inextricably tied up with questions of power, particularly focusing on how to deal with competing values and interests in processes of decision-making. Therefore, particular attention needs to be paid to power relations, whether material, economic, political, or cultural (Swyngedouw 2009). This would also include the analysis of the discourses and arguments that are mobilized to defend or legitimate particular strategies (Ibid.).

These questions of power come into play in an action situation where two or more actors are faced with a set of potential actions that jointly produce outcomes. Elinor Ostrom $(2005,32)$ refers to an action situation as the social space where participants with diverse preferences interact, exchange goods and services, solve problems, dominate one another, or fight (among the many things that individuals do in action arenas). The framework for power analysis, a particular application of the TSEIframework presented in this book (Sect. 5.2), serves to shine a light on the political dimensions of Transformative Social-Ecological Innovation, using a vertical and horizontal typology of power.

The TSEI-framework has taken the action situation as the object of analysis and considers the action situation as the interface or 'glue' between two important analytical components: structure/institutions, on the one hand, and actor-agency, on the other (Huntjens et al. 2016). 'This relates directly to one of the important debates in social science: the relationship between structure and agency. Anthony Giddens (1984) argues that social structure is both the medium and outcome of action. According to Giddens (1984) and Alexander Wendt (1987), actors have preferences which they cannot realize without collective action; based on these preferences they shape and re-shape social structures, albeit also through unintended consequences and over a longer period of time (Grin 2010, 2011). Once these social structures are in place, they shape and re-shape the actors themselves and their 
preferences. In other words, the constitution of agents and structures are not two independent sets of phenomena, meaning that structures should not be treated as external to individuals. This is what Voß and Kemp (2015) call second-order reflexivity, which is about self-critical and self-conscious reflection on processes of modernity, particularly instrumental rationality. It evokes a sense of agency, intention, and change. Here actors reflect on and confront not only the self-induced problems of modernity, but also the approaches, structures, and systems that reproduce them (Stirling 2006; Grin et al. 2004). In other words, actors have the ability (agency) to evaluate the effectiveness of their actions in achieving their objectives. This means that if actors can reproduce structure through action, they can also transform it' (cf. Huntjens et al. 2016).

The discussion on structure-agency relationships has consequences for the interpretation of institutional change as put forward by many institutionalists. 'Although institutions may have a level of permanency, in our analysis of action situations the institutions are sustained or altered by the actions of the people that reproduce or change them. It is exactly at this juncture (i.e. in the action situation) that institutions are "renegotiated" and changed. When individual behaviour diverges from stated norms, structures will be renegotiated and may change. The duality of structure applies here: social structures determine and constrain social action, on the one hand, but are reproduced, renegotiated, or changed by that same human action simultaneously (Giddens 1984). Thus, institutional change is not a process by design, but by institutionalization' (cf. Huntjens et al. 2016). The process of institutionalization is referred to as follows: '[Institutions] are the outcome of a process of institutionalization, whereby preferred ways of doing things are progressively reinforced, making them relatively reliable. This process usually involves conflict and the exercise of social power' (Parker et al. 2003, 212). In this vein, Giddens' (1984) structuration theory, as well as the work of Bourdieu (1988, 2005) and Seo and Creed (2002), provides compelling arguments for depicting institutions not only as constraints on action, but also as the objects of constant maintenance or moderation. The example of TSEI-framework application in Sect. 6.6 shows when and how local agents change the institutional context itself, which provides relevant insights on institutional work (Beunen and Patterson 2019) and the mutually constitutive nature of structure and agency.

The duality of structure and complexities of institutional change are well explained by the concept of institutional contradictions (Seo and Creed 2002), a dialectic model emphasizing that multiple models of practice, conflicting structural rules, and contradictory principles among social agents are strong driving forces for organizational and institutional change. The model of Seo and Creed (2002) also emphasizes the role of less powerful or marginalized social actors as potential change agents. Finally, this dialectical model highlights 'the pivotal role of actors' ability or skills to mobilize institutional logics and resources from the heterogeneous institutional environments so as to legitimize and support their change efforts' (cf. Seo and Creed 2002, pp. 242). Hence, Seo and Creed (2002) argue 'that institutionally embedded praxis is a far more common and important factor in institutional change than institutional theories of either orthodox compliance or 
strategic resistance suggest'. Likewise, Beunen and Patterson (2019) have used the concept of 'institutional work' to explore the interplay between actors and institutional structures. The concept of institutional work is defined as the actions through which actors create, maintain, or disrupt institutional structures (Lawrence et al. 2009). However, Beunen and Patterson (2019) point out the difficulty of fully grasping an actor's real intentions and thus to distinguish purposive actions from other actions and communications that affect institutional structures, while recognizing that institutional structures are also influenced by a range of non-purposive actions taken by disparate actors. At the same time, actors are likely to have their own ideas about who played which role in the processes of institutional change. Hence, Beunen and Patterson (2019) argue for a broader definition of 'institutional work' by not only including the intentionality of actors, but also their non-purposive actions, and by recognizing that distinguishing purposive actions from other actions can be highly problematic. This require more attention for combinations of actions and strategies that can involve multiple kinds of linked actions. The TSEI analytical framework allows to zoom in on a series or cluster of related action situations (and their context), looking at 'structure' and 'agency' and at the output-outcomes-impact of these linked action situations (for more information see Sect. 5.1). The selected action situations are then analysed, focusing in particular on subcomponents such as initiation, process, format, and content of the action situation (Sect. 5.1).

At the core of TSEI lies the engagement and participation of government, businesses, academia, civilians, civil society, media, and the environment, in a process of multi-party deliberation, collective learning, and evidence-based decision-making, which resembles the quintuple helix innovation model (Barth 2011; Carayannis and Campbell 2010), which is a follow-up to the Triple Helix model, designed by Etzkowitz and Leydesdorff (2000). The Triple Helix focuses on the relations of universities, industry, and governments and is commonly used as a key concept guiding national and regional innovation policies around the world. This model for economic growth and regional development, however, has been criticized by many scholars, among others due to its lack of context sensitivity (see, e.g. Barth 2011; Carayannis and Campbell 2010; Williams and Woodson 2012). The quintuple helix innovation model (Barth 2011; Carayannis and Campbell 2010), in short 5-Helix, adds two important components: (1) the perspective of a media-based and culture-based public and (2) it frames knowledge and innovation in the context of the environment. The quintuple helix shows how democracy and the environment need to be integrated in the wider perspective of the architecture of Transformative SocialEcological Innovation (TSEI) and societal transformation more in general.

In the Netherlands, for instance, the 5-Helix approach has become popular in the form of transdisciplinary approaches and living labs (see Sect. 4.12). Likewise, at Dutch universities of applied sciences, including my own university, it is becoming common practice to enhance cooperation within networks consisting of 5 components resembling the 5-Helix approach. In Dutch these components are called the 5 Os: Entrepreneurs (Ondernemers), Government (Overheid), Educational and Research institutions (Onderwijs- en Onderzoeksinstellingen), and Environment 
(Omgeving), including citizens and civil society organizations. With these parties, it is possible to draw up core questions on relevant themes and set up programmes to answer these questions by means of applied research and educational programmes and projects. Together, the parties involved should commit themselves to finding the people and resources required. In this book, various methodological approaches of real-world experimentation and collaborative action research are being used that make the commitment to knowledge co-production operational (see Sects. 4.10 and 5.4 in particular).

For realizing a Natural Social Contract it requires a rethink of how society could be reorganized in such a way that more problems can be solved at the most appropriate level (the subsidiarity principle) and by new coalitions in horizontal innovation networks. It will require new forms of democracy, governance, organization, management, cooperation, changing laws and legislation, and a transition from linear to circular business models. It will go hand in hand with processes of collective learning (Sect. 4.8), in which different parties learn from each other and participate in joint knowledge development. Also innovative and hybrid forms of financing, such as revolving energy and sustainability funds, will be part of this development. A fundamental systemic change required for a Natural Social Contract, at least from an economic perspective, is a transition from mainstream economic thinking - with a singular focus on economic growth and financial profittowards circular and regenerative economies and cultures (see Sects. 3.2 and 3.3), facilitated through shared value and multiple value creation (Sect. 4.9).

A Natural Social Contract may look similar to the Rhineland model in various ways, though a Natural Social Contract implies various systemic changes to improve the model's applicability to today's complex societal issues. At a more fundamental level, a Natural Social Contract provides a counter-proposal to the capitalist economic logic and divide between humans and nature, which is shaping the paradigms of both Anglo-Saxon and Rhineland models (see Sect. 3.5). Frequently mentioned drawbacks of the Rhineland model include its excessive emphasis on consultation, slow decision-making, lack for room for excellence ('mediocrity'), and ever-shifting goals due to an overestimation of the value of new insights (Bakker et al. 2005; Goodijk 2009; Peters and Weggeman 2009). A complementary approach to consultation between myriad interest groups, which is typical for the Rhineland model, is effective cooperation by new coalitions in horizontal innovation networks, also known as a coalition of the willing. Also hybrid forms of democracy, such as representative democracy complemented by deliberative democracy, could provide for better involvement of citizens and evidence-based decision-making on issues of common and public interest. New forms of governance, such as adaptive, reflexive, and deliberative governance, can help to increase stakeholder participation and commitment, community-involvement, policy learning, robust and evidence-based decision-making, flexibility and resilience to deal with shocks and surprises.

The TSEI-framework proposed in this book allows for a better understanding of and engagement with Transformative Social-Ecological Innovation (TSEI) in-the-making, not only focusing on how to govern the early stages of the process (e.g. transition arenas, niche-experiments), but also later phases of transition (for 
example, how to achieve acceleration, e.g. see (Gorissen et al. 2018; Sovacool 2016). This primarily includes research into the emergence, development and context of the partnership between various actors, and the extent to which they achieve the intended results. It requires research on what holds the actor coalitions together (e.g. shared beliefs and values, shared discourses, common interests, multiple value creation (Sect. 4.8) and procedural justice (Sect. 4.9), the roles of intermediaries in governing, facilitating, and accelerating transitions, and the role and influence of policy mixes (rather than studying single policy instruments). For more details on the research and innovation agenda see Part 3 of this book.

The result of the chosen procedure is de facto similar to the extent to which the overall goals of a Natural Social Contract are being achieved, with particular attention for TSEI outputs, outcomes, and impacts, and related to the ethical and normative aspects of a Natural Social Contract, such as social justice, equity, human security, environmental security, and planetary health. This requires development of appropriate indicators for measuring the social, ecological, and economic dimensions of sustainability transitions. Within this context, it is necessary to make a distinction between output, outcome, and impact (see Sect. 5.1 for more detail). The output could be a multi-party agreement and committed investments on Transformative Social-Ecological Innovation. Examples at the international level include the EU Green Deal, the UN Sustainable Development Goals, the Paris Climate Accord, or the Global Deal for Nature, yet to be realized at the biodiversity summit in Beijing in 2021. For other examples, at various levels, see Sect. 3.10. The outcomes are the direct effect(s) of the output. It is measurable and time-limited, though determining the full effect can take an extended period of time. Examples of outcomes include behavioural change, new knowledge, and (systemic) solutions resulting from co-creation and social learning. Specific examples constitute a circular (no waste) society and economy, preservation and restoration of biodiversity and ecosystems, and sustainable and healthy agri-food systems. Finally, impacts are the long-term or indirect effects of the outcomes and often difficult to quantify because they may or may not happen. Examples include achievement of the UN Sustainable Development Goals.

Transformative Social-Ecological Innovation (TSEI), as the engine of the sustainability transition, will help develop and implement a Natural Social Contract. Every single innovation that has the impact of a breakthrough or systemic innovation within the sustainability transition essentially constitutes a subsection of such a Natural Social Contract. Unlike hypothetical social contracts, however, TSEI can be studied empirically (see also Ziegler 2013). Chapter 6, therefore, provides various analytical instruments for empirical research into TSEI. 


\subsection{Development of a Natural Social Contract at Multiple Governance Levels}

The development and implementation of a Natural Social Contract might take place at various governance levels, ranging from the local to the national and international level:

- Local level: At the local level it is often difficult to see systemic change in-the-making, although change is often initiated at the local level through niches or front-runners, for example, in pilot projects where local entrepreneurs, citizens, and/or other parties work together to put an innovative concept for sustainability into practice. When it comes to radically new practices, insights, and values, small steps can resonate, ultimately bringing about large-scale changes (Bryson 1988). In many cases, however, this requires strategic niche management (Kemp et al. 1998; Schot and Geels 2008), transition management or governance (see Sect. 4.2), or other types of long-term support and upscaling before systemic change can be consolidated. In this book several promising examples of niches and front-runners are provided in Chaps. 6 and 7, including Food Policy Councils (FPCs), as loci for practising food democracy, community-supported agriculture (CSA), as a sustainable alternative for industrial agriculture, and short food supply chains (Chap. 6), as well as circular business models, urban commons, and examples of eco-cities (Chap. 7).

- Subnational level: At this level, depending on the area or topic in question, there are generally more opportunities for systemic change, given that programmes and collaborations at this level usually require the involvement of multiple actors in a multi-level governance context. Examples include the development and implementation of new forms of spatial and participatory planning processes for sustainable cities or river basin management or a transition approach towards sustainable agriculture at the provincial level. Illustrations in this book include 'The most sustainable square kilometre of the Netherlands' (Sect. 7.1), and the transition approach towards sustainable agriculture in the Province of South Holland (Sect. 6.6). Also the regional cooperative 'Land of Values' (In Dutch: Land van Waarde) serves as an example at the subnational or supra-local level (Sect. 6.3).

- National level: A societal transformation towards a Natural Social Contract at the national level is a complex multi-level governance challenge, requiring the finetuning of top down policy and visions with important bottom-up processes (Huntjens et al. 2011a, b; Bache et al. 2016). Sustainability transitions at the national level are certainly not only initiated or facilitated by government, but also driven by the private sector, civil society organizations, knowledge institutes, and public opinion, as explained in the previous section. Sustainable development, in particular the Sustainable Development Goals (SDGs) and the Paris Climate Agreement, has entered public opinion, domestic laws and policies in different ways and to different degrees in almost every country, even though both agreements are not legally binding but emphasize consensus-building and 
voluntary and nationally determined targets. As a consequence, the 195 countries that signed the Paris Climate Agreement have not yet devoted enough effort to reducing their greenhouse gas emissions to limit global warming to a maximum of 1.5 degrees Celsius (IPCC 2018). The UN climate panel notes that global warming is currently more likely to reach 3 degrees than 2 , let alone the targeted 1.5 degrees. At the same time, domestic laws and policies are influenced due to a country's signature to international environmental agreements or treaties that are legally binding, such as the UN Convention for the Law of the Sea (UNCLOS) on the conservation and sustainable use of marine biological diversity, the adoption of the Kigali amendment to the Montreal Protocol (to reduce emission of hydrofluorocarbons (HFCs)), international law of freshwater, or the integration of environmental considerations into investment, trade and intellectual property law (Dupuy and Viñuales 2018). In parallel, domestic policies and regulations are evolving and adapting in response to public opinion, advocacy, court rulings or parliamentary decisions, of which the latter is heavily influenced by political constellation and democratic processes. As such, a growing number of countries have recognized Rights of Nature in their legal frameworks and/or jurisprudence. Legal provisions recognizing the Rights of Nature, sometimes referred to as Earth Jurisprudence, include constitutions, national statutes, and local laws, e.g. in Uganda, Peru, Ecuador, Colombia, India, Bangladesh, New Zealand, and communities in the USA, while some countries have granted rights to rivers, e.g. the Whanganui river in New Zealand, the Yarra River in Australia, and the Ganges and Yamuna rivers in India. Constitutional amendments addressing, among others, the rights of the living, animal welfare, the global commons, the crime of ecocide, and the principle of non-environmental regression have been tabled in many parliaments, signalling a trend for a more Earth-centred constitutional process.

- EU level: In Europe, 'a good and healthy life in 2050 within our planet's ecological boundary' is a core component of environmental policy (EU, 7th Environment Action Programme 2013). This vision has also been incorporated in other lines of EU policy. In the past two decades, the European Union has introduced a large body of environmental legislation, which has succeeded in significantly reducing air, water, and soil pollution. More recently, in 2019 the new European Commission has announced a New Green Deal for Europe, which is an ambitious and pragmatic plan to transition to zero greenhouse gas emissions and transform Europe in the process. The proposed 'Green Deal' represents a unique opportunity for the EU to move away from fragmented policymaking in climate change to a comprehensive and consistent policy framework. This can promote decarbonization while also taking advantage of the economic and industrial opportunities it offers, such as circular economy, clean energy, and related job creation. In a climate-neutral Europe, all industries relying on burning fossil fuels will have to change to cleaner and renewable energy sources. At the heart of the Green Deal the Biodiversity and Farm to Fork strategies point to a new and better balance of nature, food systems, and biodiversity. 
From a legal perspective, 'modern European Union (EU) legal frameworks treat Nature as property and implicitly legalize damage through regulations which treat ecosystems as objects and not subjects of law. Traditional environmental regulatory systems generally describe nature as property to be used for human benefit, rather than a rights-bearing partner with which humanity has co-evolved. Civil society organizations have proposed changes in EU legal frameworks to account for Nature's Rights, since the purpose of the existing regulations is to establish how much damage can be done and not to prevent it and/or eradicate it' (cf. Pikramenou 2020).

- Global level: 'International processes associated with sustainable development have not led to an internationally legally binding framework that adequately addresses the challenges we face' (cf. Rühs and Jones 2016). Nevertheless, important developments on a global scale include the adoption of the United Nations Sustainable Development Goals (SDGs) and the Paris Agreement on Climate Change, although none of them is legally binding. Both agreements emphasize consensus-building and allow for voluntary and nationally determined targets. Likewise, a global nature agreement is currently being worked on, which should lead to a Global Deal for Nature at the biodiversity summit in Beijing in 2021. This is an important step towards a major reorganization of the entire economic and financial system, a global shift towards sustainability that must go hand in hand with the fight for the preservation of biodiversity and the battle against climate change. In general, values on the relationships between humans and nature are becoming more prominent and recognized at the international level in various ways. For example, the United Nations World Charter for Nature, adopted in 1982, announced five principles of conservation by which all human conduct affecting nature is to be guided and judged. Likewise, the Earth Charter-an ethical framework for sustainable development published in 2000reserves a central place for environmental protection, human rights, equitable human development, and peace and argues that these values are interdependent and indivisible. In 2010, the Universal Declaration of the Rights of Mother Earth was proclaimed at the World People's Conference on Climate Change and the Rights of Mother Earth held in Cochabamba, Bolivia. Overall, evidence suggests a growing presence of international environmental law in international legal practice (Dupuy and Viñuales 2018).

The sustainability transition implies a large-scale societal transformation towards a Natural Social Contract, in which Transformative Social-Ecological Innovation (TSEI) will be needed in different fields and at different levels of scale. These systemic innovations may occur both simultaneously and independently of each other, reinforcing each other or competing with each other. As a rule, such a transition is not a linear development but consists of a mosaic of various technological and social innovations, of which we cannot predict in advance what will and what will not work. 
Open Access This chapter is licensed under the terms of the Creative Commons Attribution 4.0 International License (http://creativecommons.org/licenses/by/4.0/), which permits use, sharing, adaptation, distribution and reproduction in any medium or format, as long as you give appropriate credit to the original author(s) and the source, provide a link to the Creative Commons license and indicate if changes were made.

The images or other third party material in this chapter are included in the chapter's Creative Commons license, unless indicated otherwise in a credit line to the material. If material is not included in the chapter's Creative Commons license and your intended use is not permitted by statutory regulation or exceeds the permitted use, you will need to obtain permission directly from the copyright holder.

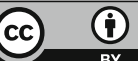

